\title{
The Power of Iron Catalysis in Diazo Chemistry
}

\section{Virginie Carreras $(1)$ \\ Nour Tanbouza \\ Thierry Ollevier ${ }^{*}$ (i)}

Département de Chimie, Université Laval, 1045 avenue de la Médecine, G1V 0A6 (QC) Québec, Canada thierry.ollevier@chm.ulaval.ca

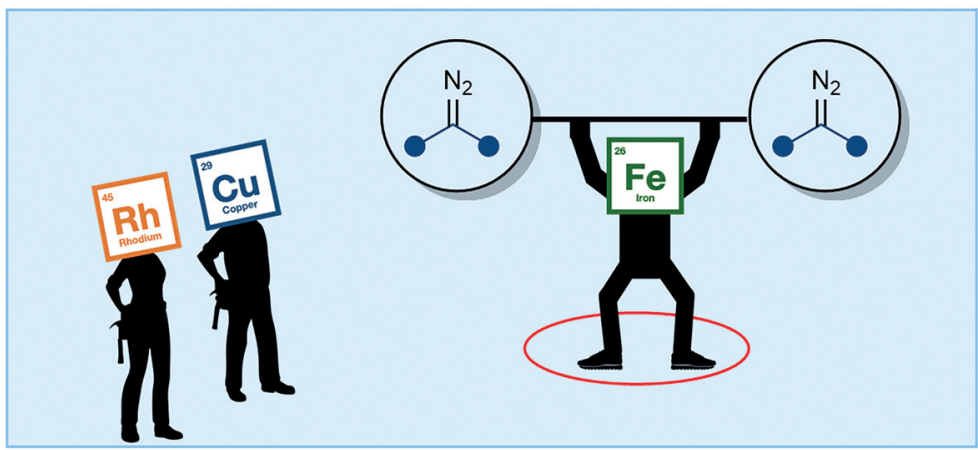

Received: 27.06.2020

Accepted after revision: 04.08.2020

Published online: 15.09 .2020

DOI: 10.1055/s-0040-1707272; Art ID: ss-2020-z0353-sr

Abstract The use of iron catalysis to enable reactions with diazo compounds has emerged as a valuable tool to forge carbon-carbon or carbon-heteroatom bonds. While diazo compounds are often encountered with toxic and expensive metal catalysts, such as Rh, Ru, Pd, Ir, and $\mathrm{Cu}$, a resurgence of Fe catalysis has been observed. This short review will showcase and highlight the recent advances in iron-mediated reactions of diazo compounds.

1 Introduction

2 Insertion Reactions

2.1 Insertion into B-H Bonds

2.2 Insertion into $\mathrm{Si}-\mathrm{H}$ Bonds

2.3 Insertion into $\mathrm{N}-\mathrm{H}$ Bonds

2.4 Insertion into $\mathrm{S}-\mathrm{H}$ bonds

3 Ylide Formation and Subsequent Reactions

3.1 Doyle-Kirmse Rearrangement

3.2 [1,2]-Stevens and Sommelet-Hauser Rearrangements

3.3 Olefination Reactions

3.4 Cycloaddition Reactions

3.5 gem-Difluoroalkenylation

4 Three-Component Reactions

5 Miscellaneous

6 Conclusion

Key words iron, diazo compounds, carbenes, insertion, olefination, green chemistry

\section{Introduction}

The pursuit of sustainable processes in organic synthesis has been critical to orient focus on the incorporation of green chemistry strategies. ${ }^{1}$ This interest mainly stems from a fast-paced and ever-growing chemical industry that demands the development of new methodologies to achieve complex target molecules while being economically and environmentally viable. 'Reduce and avoid the use or generation of hazardous material' that is the pillar of green

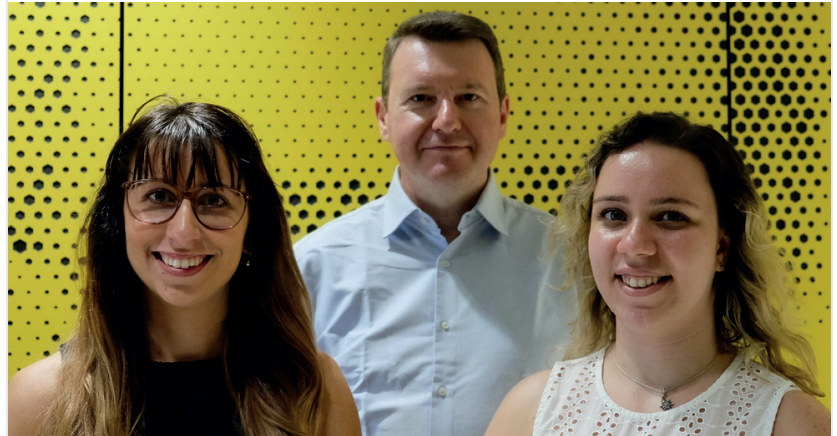

Thierry Ollevier was born in Brussels and obtained his Licence (1991) and Ph.D. (1997) at the Université of Namur (Belgium), and was a postdoctorate fellow at the Université catholique de Louvain (Belgium), under István E. Markó (1997), NATO postdoctorate fellow at Stanford low at the Université de Montréal under André B. Charette (20002001). After an Assistant Professor appointment (2001) at Université Laval (Québec, Canada), he became Associate (2006) and is currently Full Professor. Current research in his group aims at designing novel catalysts and developing catalytic reactions and then applying these methods to chemical synthesis. He is active in the areas of iron catalysis, diazo chemistry, asymmetric catalysis, and synthetic green chemistry. He has served as a member of the Advisory Board of SynOpen since 2019, as an Associate Editor of RSC Advances since 2015 and was admitted as a Fellow of the Royal Society of Chemistry (2016).

Virginie Carreras was born in Muret, France. She received her M.Sc. in fundamental and applied organic chemistry from Université Paul Sabatier (Toulouse, France) in 2016. She has been an intern in 2015 under the supervision of Professor Thierry Ollevier at Université Laval, then in 2016 under Professor David Stuart at Portland State University (Oregon, USA). She is finishing her Ph.D. in organic chemistry at Université Laval under Professor Thierry Ollevier. Her current research interest is the development of asymmetric catalysis using diazo substrates.

Nour Tanbouza was born in Montréal, Canada, and received her Licence (2015) in chemistry and Master 1 (2016) in molecular chemistry from the Lebanese University (Beirut, Lebanon). She then started her M.Sc. under the supervision of Professor Thierry Ollevier at Université Laval and in 2018 fast-tracked to a Ph.D. where she is currently working on developing reactions of diazo surrogates in continuous flow. University under Barry M. Trost (1998-2000), then postdoctorate fel- 
chemistry and among its significant contributors has been catalysis. Catalysis has emerged as a powerful tool for realizing sustainability through chemistry. Transition metals are among the most commonly employed catalysts, and that can be attributed to the variety and facile interchangeability of their stable oxidation states. However, the scarcity and toxicity of certain transition metals render them unattractive picks as catalysts. For this, iron has received considerable attention as an efficient and appropriate catalyst for a wide variety of chemical transformations.,

The fact that iron is abundant, cheap, environmentally benign, and low in toxicity makes it an appealing choice, especially when it comes to replacing precious metals, such as $\mathrm{Rh}, \mathrm{Ru}, \mathrm{Pd}$, and $\mathrm{Ir}^{5,6}$ So, it is no surprise that it has been investigated in diazo chemistry. Diazo compounds are notorious carbene precursors and are highly versatile compounds in organic synthesis. ${ }^{7,8}$ They are potent compounds for creating carbon-carbon and carbon-heteroatom bonds that would be arduous to attain otherwise. ${ }^{9}$ Diazo compounds can generate highly reactive metal carbene species in the presence of a transition metal catalyst. A metal carbene can then be used for a wide variety of reactions, notably cyclopropanation and insertion reactions. ${ }^{7-14}$ Since their initial discovery until the present day, diazo compounds have been the subject of constant research where numerous advancements have been made in this field. The most commonly employed transition metal catalysts with diazo compounds are $\mathrm{Rh}$ and $\mathrm{Cu}$, which have been highly efficient in mediating carbene reactions with high selectivities and at low loadings. ${ }^{7-13,15}$ However, these precious and toxic metals have shown equal, if not less, efficiency compared to iron catalysts in certain transformations with diazo compounds. The first iron-catalyzed reaction with diazo compounds was reported in 1994 for the cyclopropanation of olefins. ${ }^{16}$ The distinct Lewis acid character and redox properties of iron catalysts make them suitable for the activation of diazo compounds, whether through nitrogen elimination to create an iron carbene, coordination to the terminal nitrogen usually leading to ylide formation, or activation of electrophiles for nucleophilic addition (Scheme 1).

The use of iron catalysis in diazo chemistry has received mounting attention and is extensively researched for selected diazo-promoted transformations. Iron-catalyzed $\mathrm{C}-\mathrm{H}$ insertion and cyclopropanation reactions are well known and described as main routes for $\mathrm{C}-\mathrm{H}$ functionalization with many key developments in the field over the past decade. ${ }^{10-14}$ Insertion reactions into $\mathrm{C}-\mathrm{H}$ bonds catalyzed by iron complexes are highly appreciated for their efficiency, selectivity, and sustainability when compared to alternative methods to functionalize activated and non-activated $\mathrm{C}-\mathrm{H}$ bonds. ${ }^{12}$ In addition, cyclopropanation reactions of diazo compounds have been significantly studied using iron catalysts as better alternatives to precious metal catalysts. ${ }^{11}$ As a result, several reviews have comprehensively reported differ- ent aspects in the field, whereas iron-catalyzed cyclopropanation and $\mathrm{C}-\mathrm{H}$ functionalization have been recently covered in different publications. ${ }^{3,4,10-13}$ Thus, to avoid repetition with recent reviews on the topic, this short review will only highlight recent developments in iron-catalyzed transformations with diazo compounds that have been reported since 2014 while excluding C-H insertion and cyclopropanation reactions. A review by Zhou and Zhu comprehensively covers work prior to $2014 .{ }^{17}$ As such, this work provides a detailed and inclusive review of the most recent developments in the following iron-catalyzed reactions with diazo compounds: insertion into $\mathrm{X}-\mathrm{H}$ bonds $(\mathrm{X}=\mathrm{B}, \mathrm{Si}$, $\mathrm{N}$, and $\mathrm{S}$ ), ylide formation and their subsequent transformations, three-component assembly reactions, and miscellaneous reactions.

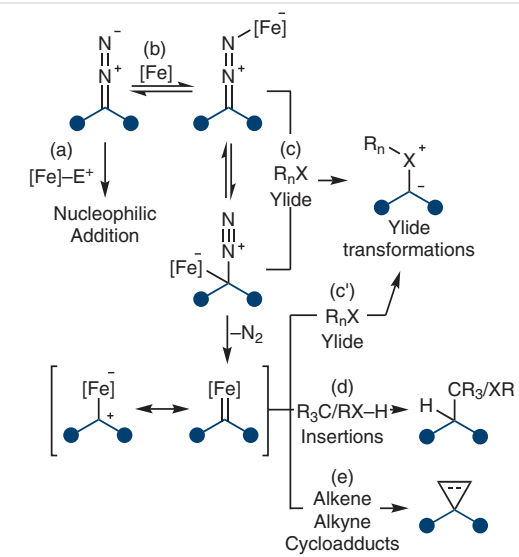

Scheme 1 Modes of reactivity between diazo compounds and an iron catalyst

\section{Insertion Reactions}

Upon activation with an iron catalyst, diazo compounds can undergo insertion reactions into $\mathrm{C}-\mathrm{H}$ or $\mathrm{C}-\mathrm{X}(\mathrm{X}=$ heteroatom) bonds. ${ }^{12,17}$ This results in the facile introduction of tailored functional groups onto the diazo center. Hence, insertion reactions are considered as one the most efficient and atom-economic methods to forge new $\mathrm{C}-\mathrm{X}$ bonds.

\subsection{Insertion into B-H Bonds}

Among the least reported insertion reactions are those involving boranes. The electron deficiency of B-H bonds renders them poor substrates because they do not readily react with Fischer-type, i.e. electron-deficient, metal carbenes. In order to overcome this poor intrinsic reactivity, borane adducts with amines or phosphines electronically enrich the $\mathrm{B}-\mathrm{H}$ bond and it can then efficiently undergo insertion reactions with metal carbenes. The first metal-catalyzed $\mathrm{B}-\mathrm{H}$ insertion reaction was performed using a $\mathrm{Rh}(\mathrm{II})$ catalyst with $\mathrm{N}$-heterocyclic carbene (NHC) boranes. ${ }^{18} \mathrm{~A}$ few examples were later disclosed using chiral $\mathrm{Cu}(\mathrm{I})$ or $\mathrm{Rh}(\mathrm{I})$ 
complexes that afforded the desired chiral organoboranes in yields as high as $96 \%$ and enantioselectivities that reach $99 \%$ ee. ${ }^{19,20}$

Iron catalysis was first employed for B-H insertion reactions of diazo compounds in 2017 . The seminal work by the Arnold group repurposed and engineered heme enzymes for use as catalysts to create $\mathrm{C}-\mathrm{B}$ bonds at the carbon center bearing the iron and produce abiological organoboron compounds. Variants of a heme protein Rhodothermus marinus cytochrome $c$ (Rma cyt $c$ ) are very active and selective biocatalysts (Scheme 2). For diazo ester insertions into $\mathrm{B}-\mathrm{H}$ bonds, bacterial Escherichia coli BL21(DE3) cells harboring wild-type Rma cyt $c$ (BOR ${ }^{\mathrm{WT}}$ ) were incubated with an NHCborane and a diazo substrate and subjected to site-saturation mutagenesis targeting active-site amino acids closest to the heme iron. ${ }^{21}$ It was found that, as for $\mathrm{Si}-\mathrm{H}$ insertions (see Section 2.2), a mutation M100D replacing the distal axial ligand substantially improves the catalytic activity. Two additional rounds of mutations (V75R and M103T) result in a generation III Rmacyt $c$ variant, termed $\mathrm{BOR}^{\mathrm{R} 1}$, that exhibits unmatched borylating activity. The iron-containing $\mathrm{BOR}^{\mathrm{R} 1}$ allowed insertion reactions of ethyl 2-diazopropanoate, with NHC-boranes to proceed on both a small scale and gram scale with high yields, excellent enantioselectivities, and exceptional total turnover numbers (TTN, calculated with respect to concentration of Rma cyt $c$ expressed in E. coli) (Scheme 2a). The borylating bacterium tolerated various NHC-boranes bearing different functionalities and is even chemoselective in the presence of olefins.

The Arnold group then tackled a scope expansion to obtain a biocatalytic platform that tolerated organofluorine compounds for enantioselective $\mathrm{B}-\mathrm{H}$ insertions to give highly versatile $\alpha-\mathrm{CF}_{3}$ organoboranes, which, unless going through a carbene $\mathrm{B}-\mathrm{H}$ insertion, would be otherwise difficult to obtain (Scheme $2 \mathrm{~b}$ ). ${ }^{22}$ The use of trifluoromethylated diazo compounds has been less investigated compared to their ester counterparts. This work was based on the hypothesis of an engineered active site that pockets the heme $\mathrm{CF}_{3}$ carbene intermediate in a way that the orientation of the $\mathrm{CF}_{3}$ group is restricted, and hence, stereoinduction of the $\mathrm{B}-\mathrm{H}$ insertion would occur. Indeed, site-saturated mutagenesis at residue V75S, which is located close to the heme co-factor, could enable expansion of the scope of diazo compounds, and so, it was used to parent additional mutation rounds. An optimal quintuple mutant of Rma cyt $c$ at residues Y44I, V75S, M99A, M100L, and M103D, denoted BOR- $\mathrm{CF}_{3}$, produced chiral organoboranes in turnovers that reach 2870 and with enantioselectivities as high as 98.5:1.5 er (Scheme 2b). Molecular dynamics simulations (MD) and DFT-optimized transition states showed that the alkyl substituent of the heme $\mathrm{CF}_{3}$ carbene intermediate is directed towards the solvent-exposed face. This allows di-

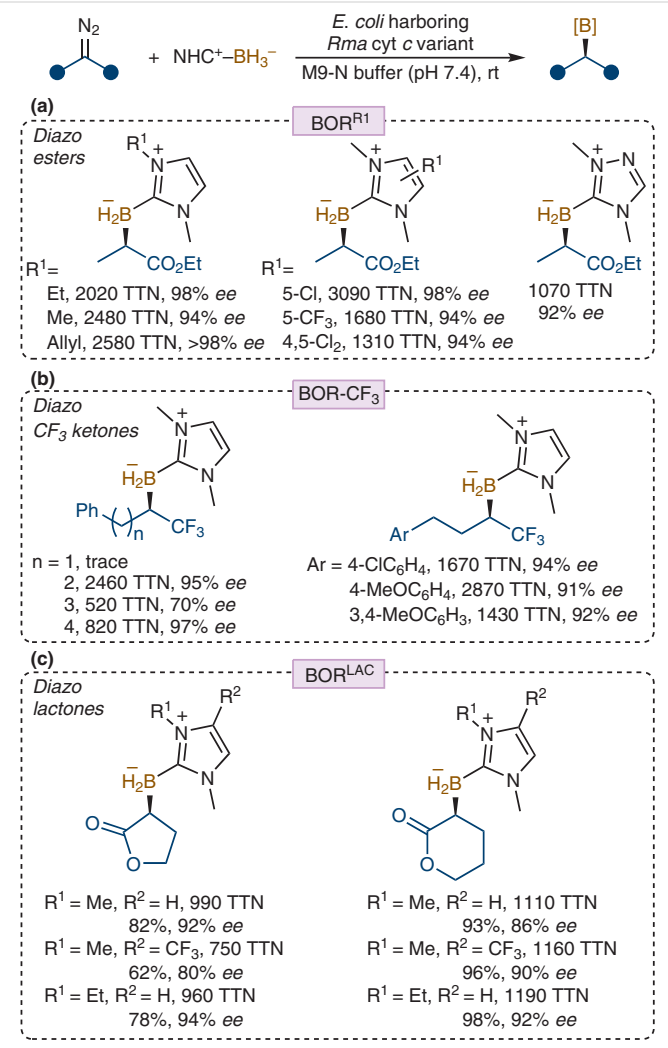

Scheme 2 Rma cyt c variant mediated B-H insertion of diazo esters, ketones, and lactones

verse 2-diazo-1,1,1-trifluoroalkane derivatives to be acceptable substrates.

Cyclic lactone diazo compounds were the next choice of compounds to experience the power of directed evolution (Scheme 2c). ${ }^{23}$ The rigidity of the resulting iron carbene intermediate was expected to exhibit distinctive conformational and electronic properties when compared to acyclic analogues. Indeed, when employing the variant $\mathrm{BOR}^{\mathrm{R} 1}$ which was used for B-H insertions with ethyl 2-diazopropanoate, high turnover and yield of borylation was obtained but with poor enantioselectivity (36\% ee). A double mutant borylating variant, $\mathrm{BOR}^{\mathrm{LAC}}$, showed a significant increase in selectivity that reached $92 \%$ ee of 5 -membered lactone diazo insertion with NHC-boranes. 6- and 7-Membered lactone substrates were also tested where the former showed high reactivity and selectivity (up to 1110 TTN and 92\% ee); however, the 7-membered lactones displayed reduced reactivity where turnover numbers dropped to $<50$ TTN. Computational studies revealed that iron carbenes derived from 7-membered lactones result in highly twisted conformations in both ground and triplet states, which is not the case for 5- and 6-membered lactone carbenes and could explain the difference in observed reactivity. 


\subsection{Insertion into $\mathrm{Si}-\mathrm{H}$ Bonds}

A decidedly atom-economic and straightforward synthesis of organosilicon compounds is the long-discovered insertion reaction of diazo compounds into $\mathrm{Si}-\mathrm{H}$ bonds. ${ }^{24,25}$ It is a useful tool to incorporate a silane moiety selectively and has been used as a key step in the synthesis of pharmaceutically relevant compounds. ${ }^{26}$ This reaction has been scrutinized with various metal catalysts, such as $\mathrm{Rh}, \mathrm{Cu}, \mathrm{Ru}$, $\mathrm{Ir}$, and Ag, and many pivotal developments have been made during these studies which have led to an excellent understanding of its mechanism and influencing factors. ${ }^{27}$

An iron-catalyzed Si-H insertion was disclosed in 2017 by the Ollevier group using a simple Fe(II) salt with $\alpha$-diazo esters (Scheme 3). ${ }^{28}$ With simple and mild conditions, $\mathrm{Fe}(\mathrm{OTf})_{2}$ at a loading of $5 \mathrm{~mol} \%$ produced the desired organosilicon compounds in high yields (up to 98\%) and short reaction times. The reaction tolerated a wide scope of diazo compounds, and both alkyl- and arylsilanes could be used. Similar to $\mathrm{Si}-\mathrm{H}$ insertions with $\mathrm{Rh}$ and $\mathrm{Cu}$ catalysts, the reaction is suggested to proceed through a concerted 3-membered pathway between the $\mathrm{Si}-\mathrm{H}$ bond and the carbon center of the iron carbene intermediate. This step was shown to be facile where no kinetic isotope effect was observed in a competition experiment with a deuterated silane. Next, the Ollevier group continued their study on iron-catalyzed $\mathrm{Si}-\mathrm{H}$ insertions while opting for a greener solvent alternative to replace the commonly required dichloromethane (DCM). ${ }^{29}$ They found that dimethyl carbonate (DMC) could be used for an $\mathrm{Fe}(\mathrm{OTf})_{2}$-catalyzed insertion reaction of $\alpha$-diazo compounds which proceeds in high yields (up to $98 \%$ ) for a wide scope of diazo compounds and silanes. The reaction mechanism of this iron-catalyzed $\mathrm{Si}-\mathrm{H}$ insertion was further examined. In DMC, also no kinetic isotope effect was observed $\left(k_{\mathrm{H}} / k_{\mathrm{D}} \mathrm{KIE}=1.04\right)$ upon competition with deuterated $\mathrm{Et}_{3} \mathrm{SiH}$. However, a large and normal nitrogen kinetic effect $\left(k_{14 \mathrm{~N}} / k_{15 \mathrm{~N}} \mathrm{KIE}=1.022\right)$ was measured at natural abundance by means of isotope ratio mass spectrometry. That, together with a first-order initial rate to the diazo compound, indicates that the formation of the iron carbene intermediate is slow compared to the insertion step.

Enantioselective $\mathrm{Si}-\mathrm{H}$ insertion reactions have been rarely used to construct stereoselectively $\mathrm{Si}-\mathrm{C}$ bonds in one step. Enantiopure organosilicon compounds are highly pertinent to medicinal chemistry where $\mathrm{Si}$ is mainly incorporated as an isostere to $\mathrm{C}$ for biological activity evaluation. ${ }^{26,30}$ For many years, chiral $\mathrm{Rh}(\mathrm{II})$ carboxylates have been the leading catalysts for this reaction. ${ }^{27}$ In 2018, Xie, Lin and co-workers developed a novel chiral spiro-bisoxazoline ligand (HMSI-BOX) which, when coupled with $\mathrm{Fe}(\mathrm{OTf})_{2}$ in 5:6 mol\% Fe/ligand loading, induced a high yielding and highly enantioselective insertion of $\alpha$-aryl- $\alpha$ diazoacetates into $\mathrm{Si}-\mathrm{H}$ bonds (Scheme 4). ${ }^{31}$ The corresponding enantiopure organosilicon compounds were obtained in up to $99 \%$ yield and $96 \%$ ee. Interestingly, $\alpha$-dia-

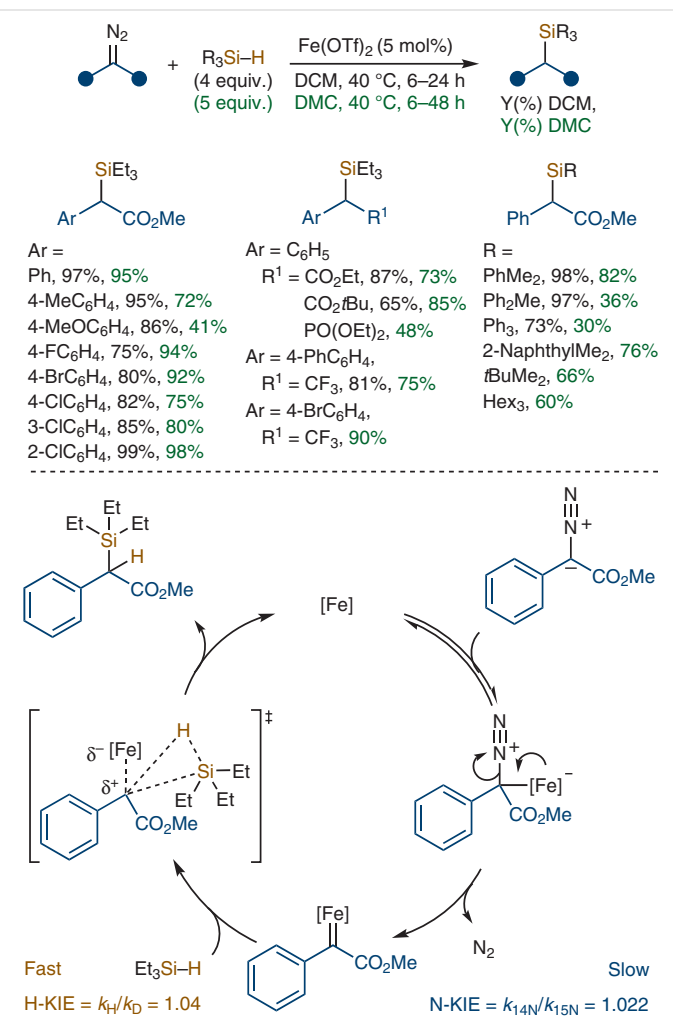

Scheme 3 First example of an iron-catalyzed insertion into $\mathrm{Si}-\mathrm{H}$ bonds using a simple iron salt $\mathrm{Fe}(\mathrm{OTf})_{2}$

zoalkylacetates showed no reactivity under the optimized reaction conditions. The enantiocontrol of HMSI-BOX was examined by DFT calculations, which revealed that a quintet state of the complex and Fe(II) species have a lower energy barrier than singlet- or triplet-state structures and that spin densities are mainly located on the Fe atom. The $R$-insertion product formation was explained by the repulsion between the ester groups and the aryl group of the ligand in the transition state.

An exquisite example that makes one reflect at the power and mystery of mother nature as the greatest chemist has been showcased in the cutting-edge work of the Arnold group through the directed evolution of enzymes. ${ }^{32} \mathrm{Her}$ work has revolutionized the field by mimicking evolution by natural selection to engineer enzymes through a sequence of mutations that can catalyze the insertion reaction of diazo compounds into $\mathrm{Si}-\mathrm{H}$ bonds. Even though silicon constitutes roughly $30 \%$ of the Earth's crust, to date enzymes that can forge $\mathrm{C}-\mathrm{Si}$ bonds are unknown in nature, meaning that organosilicon compounds are non-existent in the biological world. In this work, heme cytochrome $c$ from Icelandic, Gram-negative, thermo-halophilic bacterium Rhodothermus marinus (Rma cyt $c$ ) was initially tested for the insertion reaction of ethyl 2-diazopropanoate with dimethylphenylsilane, which produced the $\alpha$-silylated compound in $97 \%$ ee but in $<50$ TTN turnover (calculated with 


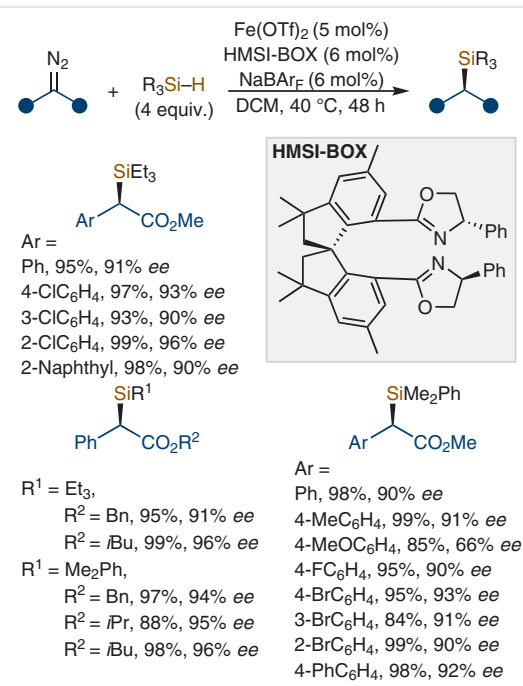

Scheme 4 Enantioselective $\mathrm{Si}-\mathrm{H}$ insertion of $\alpha$-diazo esters using the chiral HMSI-BOX ligand

respect to the concentration of Rma cyt $c$ expressed in $E$. coli) which is comparable to the activity of existing synthetic organometallic catalysts for this system. To better its activity, the team investigated the crystal structure of Rma cyt $c$ which shows that the iron is axially coordinated to a distal methionine (M100). They hypothesized that displacing M100 would facilitate the formation of the iron carbenoid. This displacement can be made by mutating its encoding amino acid and thus open up an active site in the biocatalyst and enhance its activity. After site-saturation mutagenesis of M100, the protein was expressed in E. coli which was incubated with ethyl 2-diazopropanoate and the silane. Each mutagenesis library was then cloned, screened for catalytic activity, and used to parent the next rounds of mutations. Finally, a triple mutated Rma cyt cvariant V75T M100D M103E exhibited unprecedented activity where it

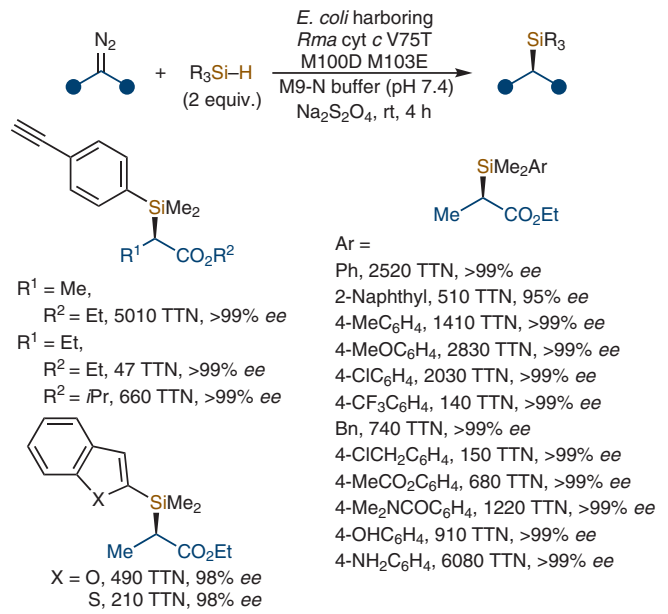

Scheme 5 Rma cyt c variant mediated Si-H insertion catalyzed the insertion reaction in $>1500$ TTN with $>99 \%$ ee (Scheme 5). The optimized biocatalyst was tolerant to an unmatched variety of diazo and silane substrates without losing activity or selectivity. The catalytically active intermediate was comprehensively evaluated through various techniques that include XRD, DFT calculation, hybrid $\mathrm{QM} / \mathrm{MM}$ approach, and molecular dynamics simulations (MD). ${ }^{33}$

These studies showed that the biocatalyst stabilized a single conformation which gives it its selectivity and that its conformational restraints favor the formation of a singlet iron-carbene.

\subsection{Insertion into $\mathrm{N}-\mathrm{H}$ Bonds}

The $\mathrm{N}-\mathrm{H}$ insertion reaction of diazo compounds is a widely applied, mild, and selective method to access amines. It is highly versatile and used to synthesize $\alpha$-amino esters, nitrogen-containing heterocycles, and dipeptides. It has also been applied for the modification of proteins by alkylating $N$-terminal amino acids. ${ }^{34,35}$ This reaction is highly dependent on the selectivity of the catalyst to proceed well, especially in the case of primary amines where a secondary (bis-insertion) is possible.

An iron-catalyzed $\mathrm{N}-\mathrm{H}$ insertion of amino acid derivatives in aqueous conditions was disclosed by Simonneaux and co-workers using an iron porphyrin complex TSPPFeCl [5,10,15,20-tetrakis(4-sulfonatophenyl)porphyrin-iron(III) chloride] (Scheme 6). ${ }^{36}$ It is a versatile water-soluble catalyst for different transformations, such as oxidations, but has been neglected for iron carbene chemistry even though other iron porphyrin complexes have been used for $\mathrm{N}-\mathrm{H}$ insertions in organic solvents. $\mathrm{N}-\mathrm{H}$ Insertions of diazo esters and diazo phosphonates with amino esters were achieved in high yields in 10 min under mild reaction conditions using $1 \mathrm{~mol} \%$ of the iron porphyrin catalyst in a $\mathrm{MeOH} /$ citratebuffered saline (CBS) buffer solution at basic $\mathrm{pH}$ at room temperature. The iron catalyst also allowed the functionalization of the $\mathrm{NH}_{2}$ terminal of insulin and is selective to a mono-insertion. Also, these reaction conditions were selective to $\mathrm{N}-\mathrm{H}$ insertion over $\mathrm{O}-\mathrm{H}$ insertion with $\mathrm{MeOH}$ or water.

Fe-porphyrin microporous organic networks (FePMN) were coated onto $\mathrm{Fe}_{3} \mathrm{O}_{4}$ nanoparticles to create a magnetically separable catalyst that was used for the carbene insertion reaction of diazo compounds into $\mathrm{N}-\mathrm{H}$ bonds (Scheme 7). ${ }^{37}$ The $\mathrm{Fe}_{3} \mathrm{O}_{4} @ \mathrm{FePMN}$ catalyst was used in a $1 \mathrm{~mol} \%$ loading and mediated the insertion of ethyl diazoacetate (EDA) with both primary and secondary amines in high yields. This work is the first demonstration of an efficient heterogeneous catalyst system for the $\mathrm{N}-\mathrm{H}$ insertion reaction. The catalyst could then be easily retrieved by merely catching it on a magnet. 


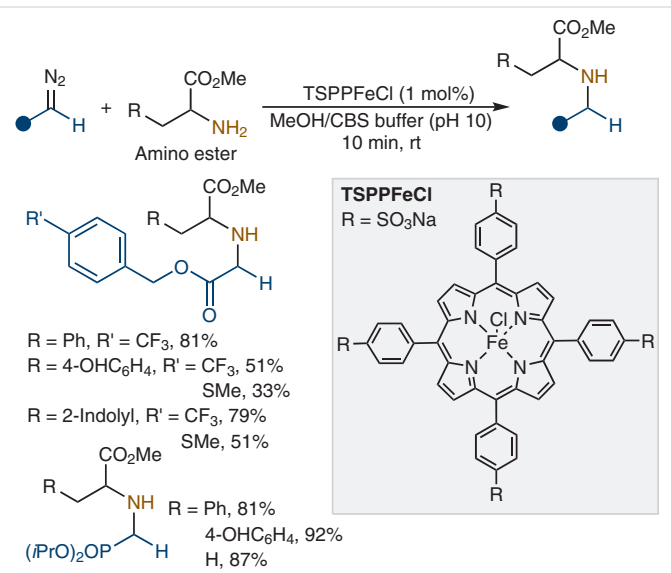

Scheme 6 TSPPFeCl-catalyzed $\mathrm{N}-\mathrm{H}$ insertion with amino esters in aqueous conditions

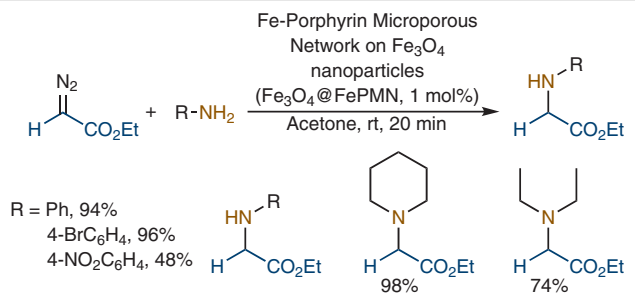

Scheme 7 Fe-porphyrin microporous organic network-catalyzed N-H insertion with $\mathrm{EDA}$

A novel class of Fe-porphyrin microporous organic nanotube networks [Fe(TTP)Cl-MONNs] were synthesized by in situ hyper-crosslinking of meso-tetraphenylporphyrin iron(III) chloride [Fe(TPP)Cl] with core-shell bottlebrush copolymers. The supported Fe-porphyrin catalyst was then applied in the $\mathrm{N}-\mathrm{H}$ insertion reaction of EDA with primary and secondary amines (Scheme 8). ${ }^{38}$ The catalyst exhibits excellent activity and is highly selective with primary amines for mono-insertions with both aryl- and alkylamines. It was observed that when using 3 equiv. of EDA, yields were relatively low for both mono- and bis-insertion products but dimerization dominated. This phenomenon showed that a second insertion is relatively slower than a

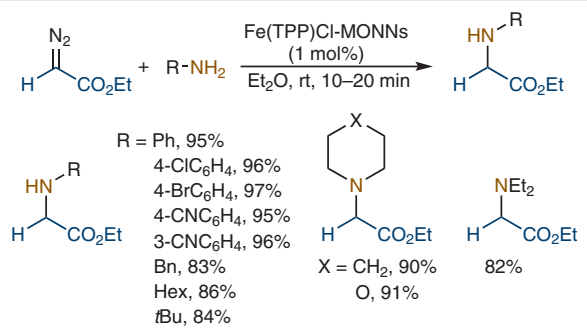

Scheme 8 Fe-porphyrin microporous organic nanotube networkcatalyzed $\mathrm{N}-\mathrm{H}$ insertion with EDA mono-insertion. The rigidity of Fe(TTP)Cl-MONNs made them highly stable, and they can be recycled up to 12 times with no leaching or loss of catalytic activity.

Quinoxalines, pyrazines, and benzoquinoxalines were readily accessed via intermolecular iron-catalyzed tandem annulation of 1,2-diamines and $\alpha$-diazocarbonyl compounds (Scheme 9). ${ }^{39}$ The reaction domino sequence is triggered by the initial $\mathrm{Fe}(\mathrm{OTf})_{3}$-catalyzed $\mathrm{N}-\mathrm{H}$ mono-insertion followed by cyclization and oxidation. The reaction was performed in water and it was high yielding while being selective towards $\mathrm{N}-\mathrm{H}$ insertion. $\mathrm{Fe}(\mathrm{OTf})_{3}$ was used in $5 \mathrm{~mol} \%$ in water with no need for any additive and showed superior activity compared to $\mathrm{Cu}, \mathrm{Ag}$, Rh, and even other $\mathrm{Fe}(\mathrm{III})$ salts. This reaction was highly tolerant in terms of scope. Mechanism elucidation shows that heating the reaction to $70^{\circ} \mathrm{C}$ is vital for the last oxidation step to occur and form the quinoxaline derivatives. Also, the Ollevier group reported $\mathrm{Fe}(\mathrm{OTf})_{2}$-mediated mono $\mathrm{N}-\mathrm{H}$ insertions of methyl $\alpha$-diazo$\alpha$-phenylacetate with various primary and secondary amines. ${ }^{29}$

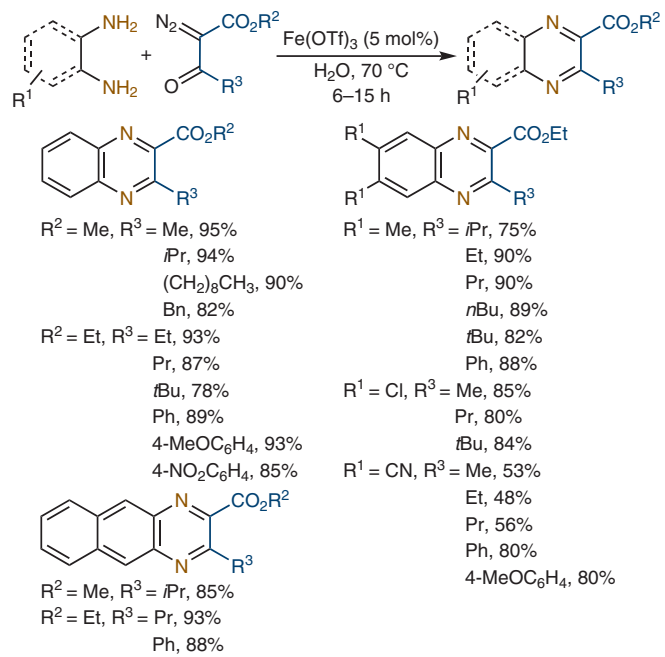

Scheme 9 Intermolecular tandem annulation of 1,2-diamines and diazocarbonyl compounds

The toxicity and explosibility of diazoacetonitrile have rendered its carbene chemistry underdeveloped in organic synthesis, despite the fact that it would serve as simple precursors to nitrile-containing compounds. Using an alternate approach, hazardous diazoacetonitrile was generated in situ in a safe and controlled continuous-flow process and subsequently used in an iron-catalyzed $\mathrm{N}-\mathrm{H}$ insertion (Scheme 10).40

The reaction setup developed by the Koenigs group was composed of a flow-batch protocol, i.e. a flow reactor was used to synthesize diazoacetonitrile from aminoacetonitrile hydrochloride and an aqueous solution of $\mathrm{NaNO}_{2}$. Then, the outlet stream was slowly added to a batch of $\mathrm{Fe}(\mathrm{TPP}) \mathrm{Cl}$ and the desired amine. This method allowed facile access to 


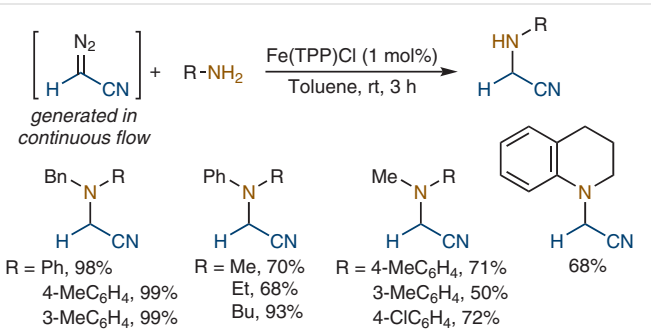

Scheme $10 \mathrm{~N}-\mathrm{H}$ Insertion reaction of in situ generated diazoacetonitrile

$\alpha$-aminonitrile compounds in excellent yields and could also be performed on a gram scale, which would have been unattainable if a strictly batch process was used. The insertion into $\mathrm{S}-\mathrm{H}$ bonds was also performed under the same conditions allowing yields as high as $99 \%$ with alkane- and arenethiols, as detailed in Section 2.4. In some cases, it was even observed that the flow process enabled high yielding $\mathrm{N} / \mathrm{S}-\mathrm{H}$ insertions with substrates that showed low reactivity in a batch process.
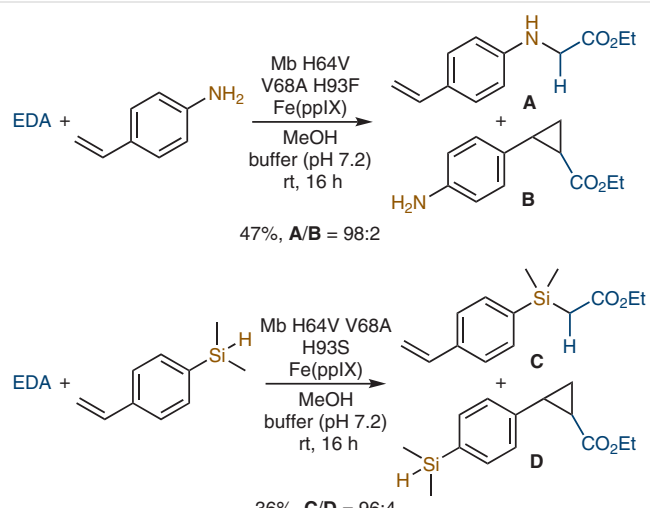

$36 \%, C / D=96: 4$

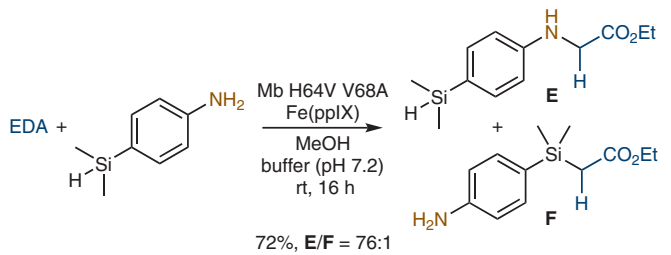

Scheme 11 Myoglobin variants directed chemoselectivity for $\mathrm{N}-\mathrm{H}$ and $\mathrm{Si}-\mathrm{H}$ insertions and cyclopropanation

After a report in 2014 of an exclusive cytochrome P450catalyzed $\mathrm{N}-\mathrm{H}$ insertion reaction (i.e., preference over a competing cyclopropanation reaction) with $p$-aminostyrene with EDA by the Arnold group, ${ }^{41}$ a directed chemoselectivity was explored by the Fasan group in 2018 (Scheme 11). ${ }^{42}$ In this work, myoglobin (Mb) variants with native histidine-ligated heme co-factor displayed the following chemoselectivity upon intramolecular competition: $\mathrm{N}-\mathrm{H}$ insertion > Si-H insertion >> cyclopropanation, however, artificial engineered myoglobin with a serine-ligated cobalt-porphyrin co-factor displayed a completely different chemoselectivity: cyclopropanation $>\mathrm{N}-\mathrm{H}$ insertion $>\mathrm{Si}-\mathrm{H}$ insertion. The latter mode of reactivity could not be attained with other biocatalysts thus showing the directionality of mutated and engineered biocatalysis.

Iron phthalocyanine complexes have also been investigated for diazo insertions with amines. Using $0.05 \mathrm{~mol} \%$ of crown ether complexed iron(III) phthalocyanine $\left(\left[(15 \mathrm{C} 5)_{4} \mathrm{PcFe}\right] \mathrm{Cl}\right)$ enabled the insertion of EDA with thiazole-, thiazoline-, and thiadiazole-substituted amines in yields ranging from 36 to $77 \%$ (Scheme 12). ${ }^{43}$ When applying an excess of EDA (2 equiv. instead of 1 equiv.), bis-insertion was observed in poor to good yields. In certain cases where the amine can tautomerize, such as with 2-aminothiazoline, two products were obtained from a bis-insertion of the 2 amine/imine tautomers in the presence of 2 equiv. of EDA.

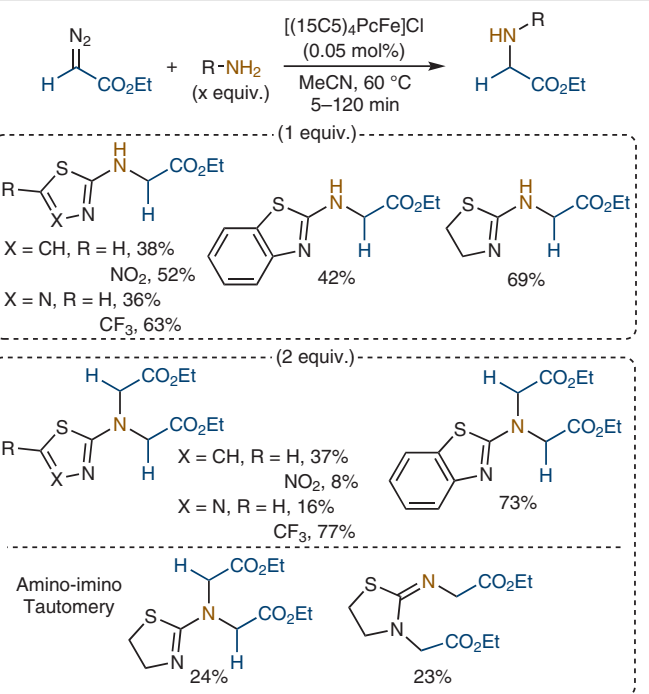

Scheme $12 \mathrm{~N}-\mathrm{H}$ Insertion mediated by an iron phthalocyanine complex bearing crown ether substituents
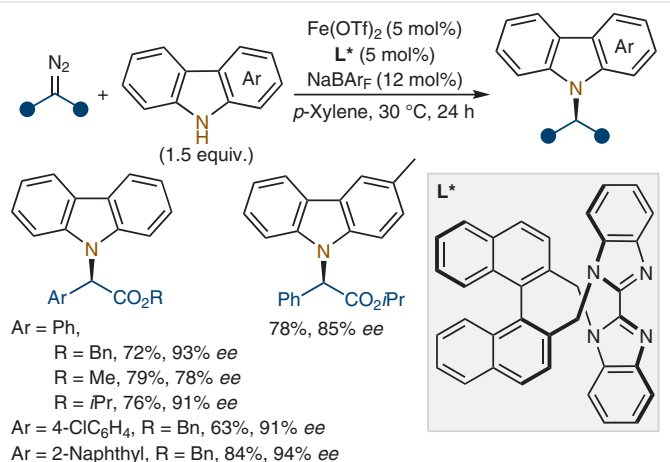

Scheme 13 Enantioselective $\mathrm{N}-\mathrm{H}$ insertion reaction of diazo esters with carbazoles 
A highly efficient and enantioselective $\mathrm{N}-\mathrm{H}$ insertion reaction of $\alpha$-aryl- $\alpha$-diazoacetates with carbazoles was achieved using a chiral iron complex with an axially chiral 2,2'-biimidazole ligand developed by Zhou and co-workers (Scheme 13). ${ }^{44}$ This novel ligand, synthesized in a single step from readily available 2,2'-bis(bromomethyl)-1,1'binaphthalene and 2,2'-biimidazole, when coupled with $\mathrm{Fe}(\mathrm{OTf})_{2}$ enabled the production of enantiopure $\alpha$-amino esters in up to $96 \%$ ee. The reaction conditions were mild and used the catalyst in $5 \mathrm{~mol}$ \% loading with $\mathrm{NaBAr}_{\mathrm{F}}$ in 12 mol\% as an additive with $p$-xylene as the solvent at $30^{\circ} \mathrm{C}$.

\subsection{Insertion into S-H Bonds}

The insertion reaction of diazo compounds into $\mathrm{S}-\mathrm{H}$ bonds dates back to $1952^{45}$ and since then, various metal catalysts have been developed to mediate this reaction, namely those based on In, Sc, Rh, and Cu. It is a facile method to access useful sulfur-containing building blocks. Iron catalysis has been reported in a few examples which mainly use iron(III) corroles and porphyrins. In 2019, the Ollevier group were able to showcase a simple iron salt $\left[\mathrm{Fe}(\mathrm{OTf})_{2}\right]$ as an efficient catalyst for the insertion reaction of $\alpha$-diazo esters and unprecedented $\alpha$-diazo ketones with both alkaneand arenethiols (Scheme 14). ${ }^{46}$ The reaction used $\mathrm{Fe}(\mathrm{OTf})_{2}$ at $10-20 \mathrm{~mol} \%$ loading at $40{ }^{\circ} \mathrm{C}$ in DCM to give the S-H insertion products in up to $96 \%$ yield. Control experiments and a H/D KIE study pointed towards a stepwise mechanism that involves the attack of the thiol on the iron carbene intermediate leading to an ylide intermediate that dissociates to give the targeted insertion product.

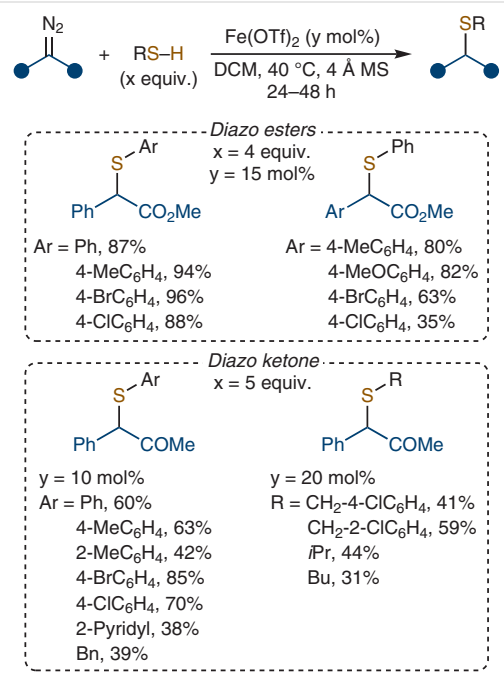

Scheme $14 \mathrm{~S}-\mathrm{H}$ Insertion reaction of $\alpha$-diazo esters and unprecedented $\alpha$-diazo ketones

Multiple studies with various catalysts have shown that the reaction proceeds stepwise and involves a sulfur ylide intermediate that could easily dissociate from the metal catalyst. ${ }^{47}$ This behavior has rendered the development of an enantioselective $\mathrm{S}-\mathrm{H}$ insertion difficult and requires the design of specific ligands to transfer chirality. ${ }^{48}$ Besides, thiols are reported to poison various chiral catalysts during this reaction. Thus, only a handful of attempts have been slightly successful in improving enantioselectivities, but with limited effectiveness. Engineered myoglobin, harvested from whale sperm, was disclosed for this reaction by the Fasan group but with best entries at $49 \%$ ee. ${ }^{49}$ Based on this work, the Arnold group investigated cytochrome P450 variants as better candidates. Indeed, unmatched catalytic activity and excellent enantioselectivities and turnover numbers were obtained using $E$. coli harboring cytochrome variant P450-G8S, which exhibited very distinct modes of reactivity when used for $\mathrm{S}-\mathrm{H}$ insertion reactions (Scheme 15). ${ }^{50}$ The biocatalyst was employed for the $\mathrm{S}-\mathrm{H}$ insertion of diazo lactones with arenethiols to give 3-(arylthio)tetrahydrofuran-2-ones. DFT studies revealed that the reaction is stepwise and involves a single hydrogen-atom transfer (HAT) followed by the combination of heme-bound carbene with a thiyl radical when an axial Cys-ligated P450 enzyme is employed, thus leading to high selectivities. When the axial Cys is replaced by Cys-to-Ser mutation, the axial Serligated P450 enzyme forms 3-(arylthio)tetrahydrofuran-2ones with low selectivity and efficiency and this is explained by a favored C-Fe homolytic cleavage due to the higher electronegativity of oxygen (Ser) compared to sulfur (Cys) and thus this erodes the stereoselectivity.

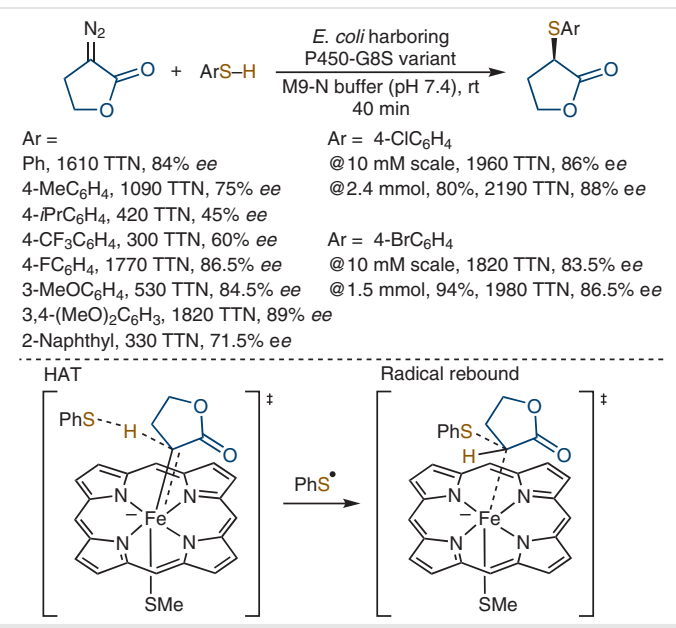

Scheme 15 Cytochrome variant P450-G8S catalyzed S-H insertion of diazo lactones

\section{Ylide Formation and Subsequent Reac- tions}

Electrophilic metal carbene species can react with nucleophilic heteroatom-containing species, such as sulfides, ethers, selenides, amines, and halides, to prepare zwitterionic, i.e. ylide species. Ylide preparation from transition- 
metal-catalyzed decomposition of diazo compounds is usually run under neutral conditions as opposed to other traditional methods which require basic conditions. Ylides are highly reactive intermediates that are used for the construction of highly functionalized building blocks. Ylides from metal carbenes can undergo subsequent inter- or intramolecular reactions in addition to cascade transformations leading to the assembly of complex organic compounds starting from relatively simple reactants. ${ }^{9,51}$ Thus, ylide formation via diazo compounds is a powerful $\mathrm{C}-\mathrm{C}$ bond-forming method in organic synthesis, and, as such, much work has been done to harvest their reactivity.

\subsection{Doyle-Kirmse Rearrangement}

Symmetry allowed [2,3]-sigmatropic rearrangements of electrophilic metal carbene species with allyl or propargyl nucleophiles have been mainly investigated with $\mathrm{Rh}, \mathrm{Cu}$, and Co metal catalysts. ${ }^{51}$ Few reports of the Doyle-Kirmse reaction were reported to involve iron-based catalysts that could produce the desired homoallylic or allenic compounds in high yields and selectivities. The Fasan group reported the first biocatalytic Doyle-Kirmse rearrangement of diazo esters with allyl sulfides in 2016 (Scheme 16). ${ }^{52}$ Active-site mutation of whale sperm myoglobin resulted in a triple-mutant variant Mb L29S H64V V68F which showed superior activity for an enantioselective catalytic DoyleKirmse rearrangement. The desired allyl sulfides were obtained with high turnover numbers (up to 8820 TTN); enantioselectivities varied highly from 0 to $71 \%$ ee depending on the diazo substrate used. It is proposed that the enantiocontrol stems from stereoretention during the rearrangement step of the 'chiral' sulfonium ylide intermediate. The Mb catalyst was assumed to be responsible for orienting the attack of one of the sulfide's lone pairs onto the heme-carbene and/or the other way around, i.e. enforce a single face

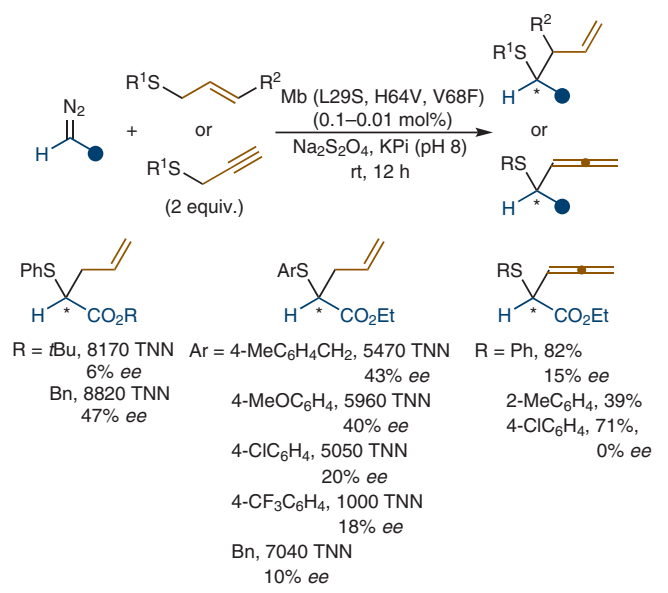

Scheme 16 Enantioselective biocatalytic Doyle-Kirmse rearrangement of the heme-carbene to be exposed to the sulfide. To date, Mb L29S H64V V68F variant remains the superior iron catalyst in terms of enantioselectivity for the Doyle-Kirmse rearrangement.

In 2017, the Koenigs group used $\mathrm{Fe}(\mathrm{TPP}) \mathrm{Cl}$ to catalyze an on-water Doyle-Kirmse rearrangement of in situ generated diazo compounds with allylic and propargylic sulfides (Scheme 17). ${ }^{53}$ In this work, diazoacetonitrile was prepared in situ by the slow addition of aqueous $\mathrm{NaNO}_{2}$ to a solution of aminoacetonitrile hydrochloride, $\mathrm{Fe}$ (TPP) $\mathrm{Cl}$ ( $1 \mathrm{~mol} \%$ ), and the sulfide in a $\mathrm{H}_{2} \mathrm{O} / \mathrm{DCM}$ mixture. The reaction scope of aliphatic, aromatic, and heteroaromatic allyl sulfides produced the desired homoallylic nitrile compounds in excellent yields (up to 99\%). Propargylic sulfides afforded the corresponding allenes as rearrangement products in very good to excellent yields. The reaction scope was also extended to various diazo compounds which tolerated 2,2,2trifluorodiazoethane, EDA, and other diazoacetates.

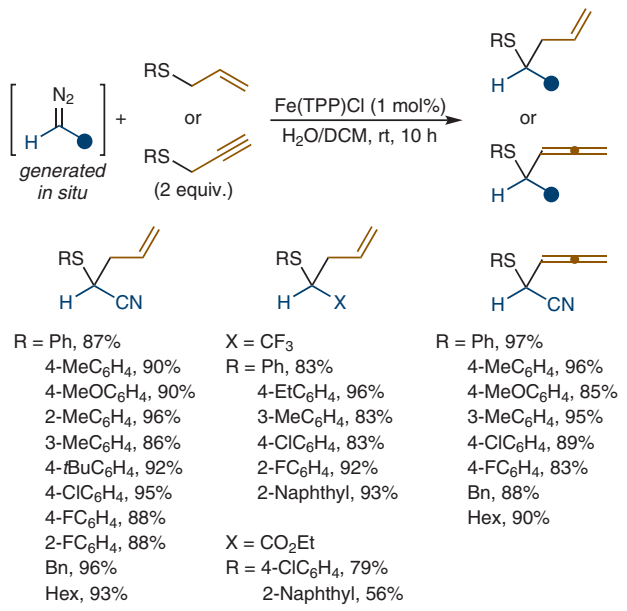

Scheme $17 \mathrm{Fe}(\mathrm{TPP}) \mathrm{Cl}$-catalyzed Doyle-Kirmse rearrangement of in situ generated diazo compounds in binary solvent mixture $\mathrm{H}_{2} \mathrm{O} / D C M$

2,2,2-Trifluorodiazoethane was generated in situ from a bench-stable crystalline surrogate, trifluoroacetaldehyde $\mathrm{N}$ [2-(trifluoromethyl)phenylsulfonyl]hydrazone (trifluoroacetaldehyde $\mathrm{N}$-tfsylhydrazone, TFHZ-Tfs) by the Bi group. Upon basic treatment, 2,2,2-trifluorodiazoethane was generated in a controlled manner and this bypasses the traditional need for slow addition procedures and acidic conditions. This novel surrogate thus reduces exposure and manipulation of the toxic and explosive diazo compound in batch conditions. The in situ generated diazo compound was reacted with 3 mol\% of Fe(TPP)Cl and used for a DoyleKirmse rearrangement with allylic and propargylic sulfides (Scheme 18)..$^{54}$ The reaction was performed in a NaOH/DCM mixture at $40{ }^{\circ} \mathrm{C}$ to produce homoallyl and allenyl $\mathrm{CF}_{3}$ sulfides in excellent yields while tolerating a broad range of sulfides. 


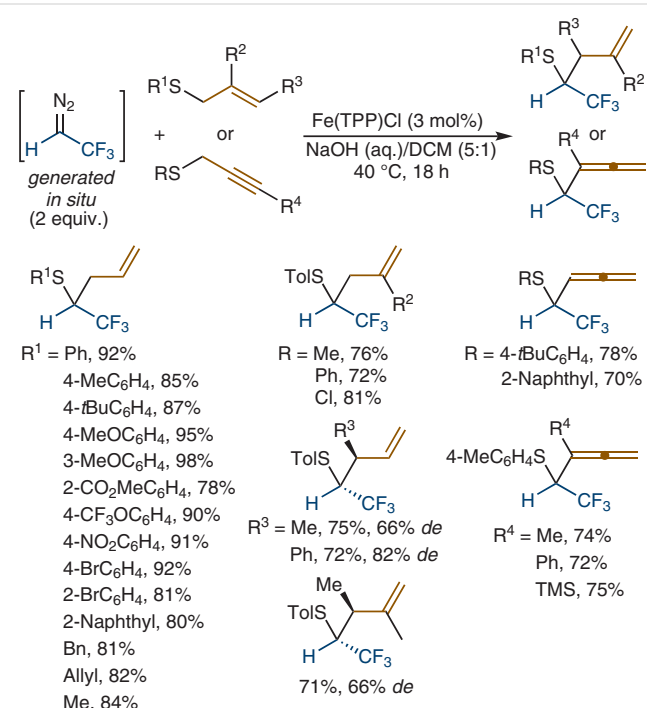

Scheme 18 Doyle-Kirmse rearrangement of 2,2,2-trifluorodiazoethane

Application was also extended to gem-difluoroalkenylation (see Section 3.5). The Bi group then investigated $\mathrm{N}$-[2(trifluoromethyl)phenylsulfonyl]hydrazones as surrogates for diazoacetaldehyde and difluorodiazoethane for ironcatalyzed Doyle-Kirmse rearrangements. ${ }^{55}$

Hemin is a native water-soluble iron porphyrin complex that has also been reported as an efficient catalyst for a [2,3]-sigmatropic rearrangement of diazo esters with allyl sulfides under strictly aqueous conditions. The reaction was reported with yields of up to $99 \%$ using $2.5 \mathrm{~mol} \%$ of hemin in $\mathrm{H}_{2} \mathrm{O}$ at $40{ }^{\circ} \mathrm{C} .{ }^{56}$

\section{$3.2[1,2]-$ Stevens and Sommelet-Hauser Rear- rangements}

Carbene-derived ylides with benzyl migrating groups result in competing [1,2]- and [2,3]-migrations, also known as $[1,2]$-Stevens and Sommelet-Hauser rearrangements, respectively. This competition is dependent on various factors which include temperature, ring strain, solvent, and substitution effects. Enhanced selectivity has been disclosed with ammonium and iodonium ylides, but sulfonium ylides have been less reported with improved rearrangement selectivity. In 2017, sulfonium ylides derived from an iron carbene were used to advantage by the Pan group by employing hemin, a native iron porphyrin complex, as the catalyst (Scheme 19). ${ }^{57}$ Upon optimization of the [1,2]-Stevens rearrangement, the heme catalyst, EDA, and benzyl phenyl sulfide allowed the formation of the desired rearranged product in $85 \%$ in THF at $80{ }^{\circ} \mathrm{C}$.

The heme biocatalyst showed superior reactivity and selectivity compared to $\mathrm{Cu}, \mathrm{Pd}$, and $\mathrm{Rh}$ catalysts. The reaction was tolerant to a variety of sulfides and showed the

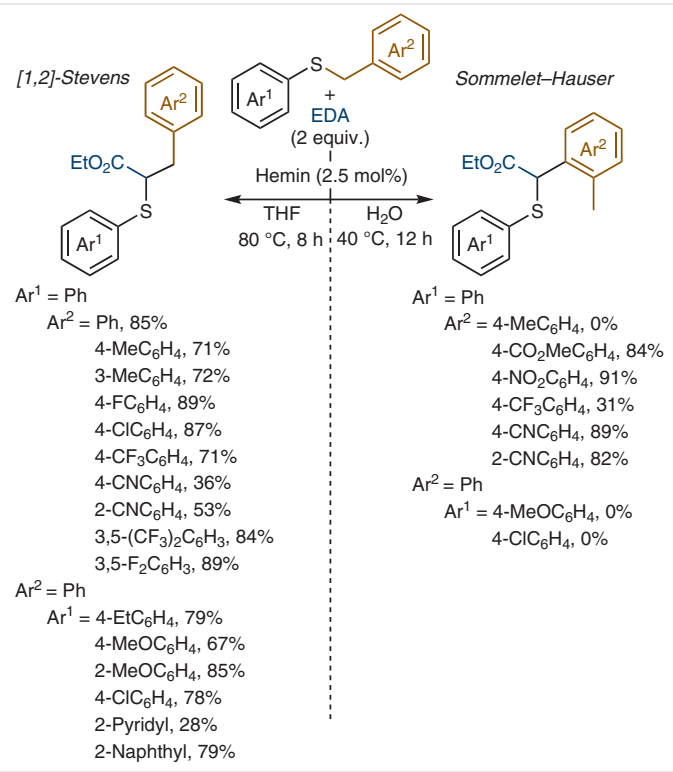

Scheme 19 Directed hemin-catalyzed [1,2]-Stevens and SommeletHauser rearrangements

opposite trend to ammonium ylides where aryl substituents with electron-withdrawing groups accelerated the competing Sommelet-Hauser rearrangement. Then, in order to favor the latter, a new set of reaction conditions were examined. Using hemin with the same catalyst loading (2.5 mol\%) and switching the reaction solvent for $\mathrm{H}_{2} \mathrm{O}$ while lowering the temperature to $40{ }^{\circ} \mathrm{C}$ directed a favored Sommelet-Hauser rearrangement with electron-poor sulfides in yields of up to $91 \%$.

The Koenigs group have examined the in situ generation of diazoacetonitrile for iron-mediated chemistries. After successful $\mathrm{N}-\mathrm{H}$ and $\mathrm{S}-\mathrm{H}$ insertions to access hitherto inaccessible nitrile compounds and based on the previous work of the Pan group ${ }^{57}$ with selective hemin rearrangements, the group explored the reactivity of diazoacetonitrile with benzyl phenyl sulfide for [1,2]-Stevens and SommeletHauser rearrangements. However, when using iron(II) phthalocyanine (FePc) in a biphasic $\mathrm{H}_{2} \mathrm{O} / \mathrm{CHCl}_{3}$ solution, neither rearrangements were observed and instead, dealkylation of the sulfur ylide leading to a formal functional group metathesis reaction was observed (Scheme 20). ${ }^{58}$ This novel rearrangement interception led to (alkylthio)and (arylthio)acetonitriles in yields of up to 95\%. A substitution effect was still observed, and the use of sulfides bearing electron-withdrawing groups led to the SommeletHauser rearrangement in moderate to low yields, but no effect was observed with electron-donating groups. This serendipitous reactivity was further investigated with other in situ generated acceptor-only diazo compounds, and the intercepted rearrangement products were obtained in moderate to high yields despite the fact that substrates such as EDA were reported to undergo [1,2]-Stevens rearrange- 
ment. It was hypothesized that this striking reactivity is due to the in situ diazo generation approach which uses the amine hydrochloride salt and aqueous $\mathrm{NaNO}_{2}$. Hence, it is proposed that the $\mathrm{H}_{2} \mathrm{O}$ protonates the ylide intermediate to give a sulfonium salt that undergoes nucleophilic substitution with the chloride of the amine hydrochloride salt as a result this intercepts the rearrangement step and thus results in the $\alpha$-sulfanyl products and benzyl chloride. In 2020, the Pan group observed the dealkylative interception of 2,2,2-trifluorodiazoethane and allyl sulfides using hemin as the catalyst. ${ }^{59}$

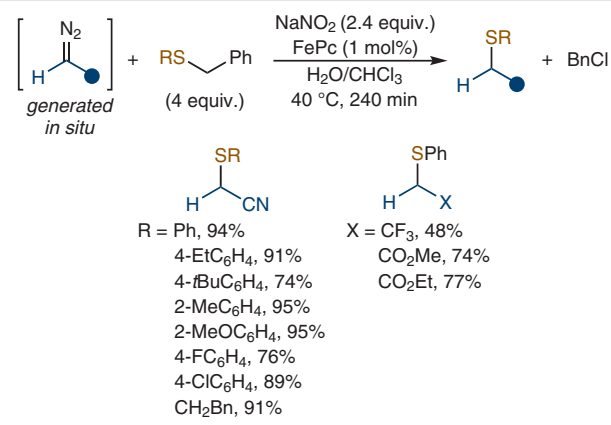

Scheme 20 Iron(II) phthalocyanine mediated dealkylation of sulfur ylides

\subsection{Olefination Reactions}

An alternative to a direct Wittig reaction for the creation of $\mathrm{C}=\mathrm{C}$ bonds from $\mathrm{C}=\mathrm{O}$ bonds is olefination with diazo compounds in the presence of a metal catalyst and a phosphine. The reaction involves the attack of the phosphine species on the metal carbene which creates a phosphonium ylide that performs a 'Wittig' reaction with an aldehyde to produce the alkene. The use of iron porphyrins has dominated in this area as efficient catalysts for high yields and $E / Z$ selectivities. Iron(IV) corroles were primarily investigated for olefinations by Chang, Liu, and co-workers (Scheme 21). ${ }^{60}$ In this work, the olefination of aldehydes with EDA and $\mathrm{PPh}_{3}$ efficiently produced $E$-alkenes with high selectivities using $1 \mathrm{~mol} \%$ of the iron(IV) corrole complex. The use of various aldehydes was examined under optimal conditions, and the reaction was generally high yielding and $E$-selective. The reaction is proposed to proceed via a phosphazine to ylide pathway as seen by ${ }^{31} \mathrm{P}$ NMR and as previously suggested for molybdenum-mediated olefinations. This mechanism was later elucidated by studies conducted by Kühn and co-workers. ${ }^{61}$

$\mathrm{Fe}(\mathrm{TPP}) \mathrm{Cl}$ functionalized microporous organic nanotube networks [Fe(TPP)Cl-MONNs] were revealed as novel catalysts for carbene insertions with amines (for more details see Section 2.3, Scheme 8) and were also efficient catalysts for the olefination of aldehydes with EDA and $\mathrm{PPh}_{3}$ (Scheme $22){ }^{38}$ The iron-functionalized microporous organic nano-

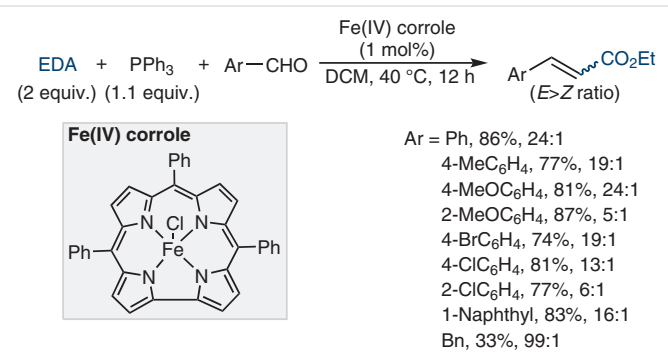

Scheme 21 Olefination of phosphonium ylides with iron(IV) corroles

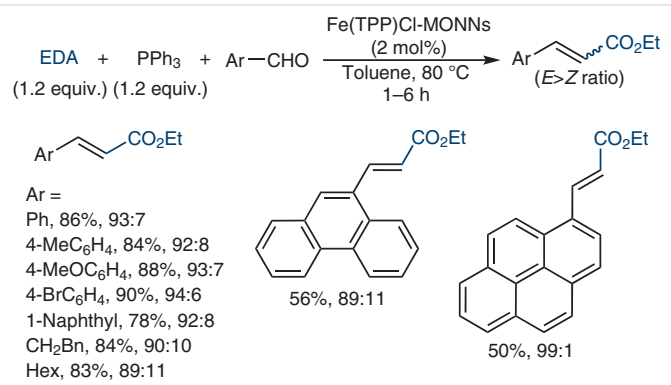

Scheme 22 Olefination of EDA with Fe(TPP)Cl functionalized microporous organic nanotube networks

tube network catalyst exhibited exceptional performance and recyclability in olefination reactions with high $E / Z$ selectivity.

\subsection{Cycloaddition Reactions}

A simple Fe(III) salt catalyzed a [2+2+1] cycloaddition of diazo surrogates with hexahydro-1,3,5-triazines as formal 1,4-dipoles. ${ }^{62}$ This reaction was previously developed with Au catalysis, but was strictly applicable only for cycloadditions with donor/acceptor diazo compounds. Continued research found that $\mathrm{Fe}(\mathrm{acac})_{3}$ enabled cycloadditions of both donor/acceptor diazo compounds and donor/donor diazo surrogates (Scheme 23). Donor/donor hydrazones were used as diazo surrogates by in situ oxidation using $\mathrm{MnO}_{2}$. The diazo compound was subsequently reacted with $\mathrm{Fe}(\mathrm{acac})_{3}$ in $5 \mathrm{~mol} \%$ and hexahydro-1,3,5-triazines to generate the cycloaddition products in moderate to high yields reaching $84 \%$. Bench-stable donor/acceptor diazo compounds were used directly in this reaction and generated the cycloaddition products in high yields of up to $80 \%$. The reaction proceeds through the formation of a nitronium ylide derived from the iron carbene and $\mathrm{N}$-methyleneamine (generated in situ from the hexahydro-1,3,5-triazine) which subsequently undergoes a $[2+2+1]$ cycloaddition with a second $\mathrm{N}$-methyleneamine to produce the target 5membered heterocycle.

An iron-aluminum porphyrin MOF (Fe-Al-PMOF) was investigated with EDA and it was demonstrated that it leads to the formation of pyrazoline in high yields by the cyclo- 
addition reaction of EDA with diethyl maleate and diethyl fumarate. ${ }^{63}$ This type of reactivity is not observed with homogenous Fe porphyrin analogues and an unusual increase in selectivity was observed after catalyst recycling.

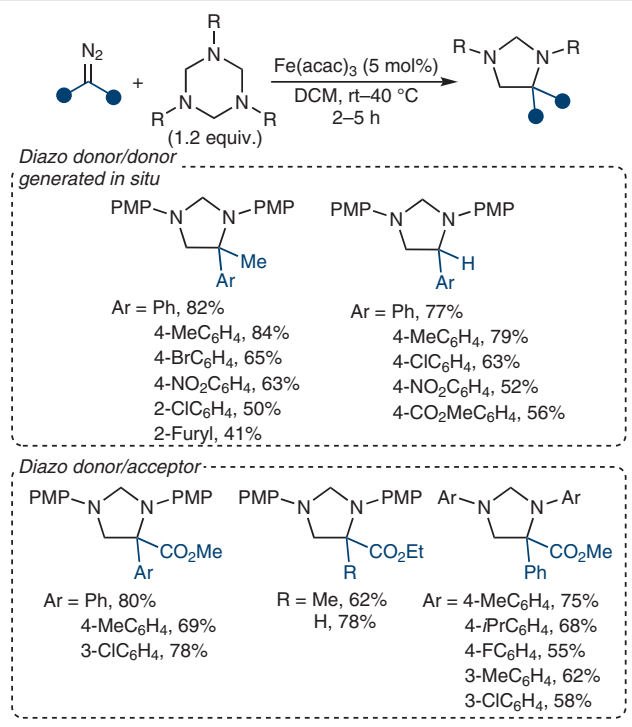

Scheme $23[2+2+1]$ Cycloaddition of diazo surrogates

\section{5 gem-Difluoroalkenylation}

In an intriguing study to synthesize difluoroalkenes, the difluoroalkenylation of $\mathrm{S}-\mathrm{H}$ and $\mathrm{Se}-\mathrm{H}$ bonds with trifluorodiazoethane [made in situ from a novel precursor, i.e. trifluoroacetaldehyde $\quad \mathrm{N}$-[2-(trifluoromethyl)phenylsulfonyl]hydrazone (TFHZ-Tfs)] was mediated by Fe(TPP)Cl (Scheme 24). ${ }^{54}$ Treating the surrogate with base produced the diazo compound in a controlled manner and eliminated the need for slow addition, which is the usual protocol when handling trifluorodiazoethane under batch conditions. The in situ generated diazo compound was decomposed in the presence of $1 \mathrm{~mol} \%$ of $\mathrm{Fe}(\mathrm{TPP}) \mathrm{Cl}, 30 \mathrm{~mol} \%$ of sodium dodecylbenzenesulfonate (SDBS), and the thiol or selenol to pro-

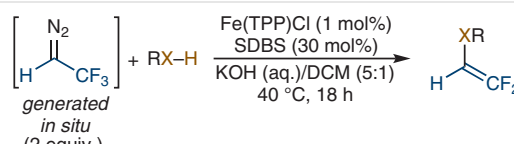

$$
\begin{aligned}
& \text { (2 equiv.) } \\
& \mathrm{R}=4-\mathrm{MeC}_{6} \mathrm{H}_{4}, 80 \% \\
& 4-\mathrm{MeOC}_{6} \mathrm{H}_{4}, 77 \% \\
& \text { 3- } \mathrm{MeOC}_{6} \mathrm{H}_{4}, 86 \% \\
& \begin{array}{l}
3-\mathrm{MeOC}_{6} \mathrm{H}_{4}, 86 \% \\
2-\mathrm{MeOC}_{6} \mathrm{H}_{4}, 72 \%
\end{array} \\
& \begin{array}{l}
2-\mathrm{MeOC}_{6} \mathrm{H}_{4}, 72 \% \\
2-\mathrm{Me}_{2} \mathrm{C}_{6} \mathrm{H}_{3}, 81 \%
\end{array} \\
& \text { 4- } \mathrm{tBuC}_{6} \mathrm{H}_{4}, 75 \% \\
& \text { 4- } \mathrm{PhC}_{6} \mathrm{H}_{4}, 50 \% \\
& 4-\mathrm{CF}_{3} \mathrm{C}_{6} \mathrm{H}_{4}, 58 \% \\
& \begin{array}{l}
4-\mathrm{CF}_{3} \mathrm{C}_{6} \mathrm{H}_{4}, 58 \% \\
4-\mathrm{H}_{4}, 51 \%
\end{array} \\
& 3-\mathrm{FC}_{6} \mathrm{H}_{4}, 54 \% \\
& 3-\mathrm{ClC}_{6} \mathrm{H}_{4}, 62 \% \\
& \text { 2-Naphthyl, } 81 \% \\
& \text { 2-Thienyl, } 55 \%
\end{aligned}
$$

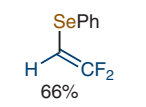

Scheme 24 gem-Difluoroalkenylation of S-H and Se-H bonds with trifluorodiazoethane duce the respective difluoroalkene in high yields. It was postulated that the attack of the thiol/selenol on the iron carbene gives the iron ylide intermediate which, upon deprotonation, undergoes $\beta$-fluoride elimination to produce the observed difluoroalkene while regenerating the iron catalyst.

\section{Three-Component Reactions}

Diazo compounds can be used to achieve high structural complexity via three-component assembly reactions. These atom-economic domino reactions are mainly triggered by the metal-catalyzed decomposition of diazo compounds which, in the presence of compatible and multifunctional substrates, undergo subsequent additions, condensations, cycloadditions, etc. ${ }^{64-68}$ It is noteworthy to mention that the three-component reactions listed here proceed through the formation of ylide intermediates (even though they have been given a separate class in this review) which then subsequently react further.

The catalytic formation of pyridinium ylides from diazo compounds and $\mathrm{Fe}(\mathrm{TPP}) \mathrm{Cl}$ with various pyridines was employed for the three-component stereoselective synthesis of tetrahydroindolizines (Scheme 25). ${ }^{64,65}$ Using EDA in the presence of $1 \mathrm{~mol} \%$ of $\mathrm{Fe}(\mathrm{TPP}) \mathrm{Cl}$ in toluene at room temperature, a three-component assembly with pyridines and oxindoles produced the desired tetrahydroindolizines in high yields and diastereoselectivities while releasing $\mathrm{N}_{2}$ as the only byproduct. Various pyridine derivatives and oxindoles underwent this pyridinium ylide triggered threecomponent assembly. This study was conducted with either iron or copper catalysts where both exhibited efficient catalytic activity. The synthesis of tetrahydroindolizines starts by the formation of the pyridinium ylide which undergoes 1,4-addition onto the alkenyloxindole and, finally, cyclization of the zwitterionic intermediate.

The diastereoselectivity arises from the minimization of dipole-dipole repulsion. Also, during the ring-closing step, the attractive interaction between the electron-deficient pyridinium ring and electron-rich oxindole results in the observed configuration of the products. The diazo compounds were also generated in situ by basic treatment of its tosylhydrazone surrogate, and the reaction proceeded in moderate yield (57\%). $\mathrm{N}$-Methylmaleimide, as an alternate electrophilic alkene to oxindoles, reacted in excellent yield with 4-(trifluoromethyl)pyridine (94\%) and good yield with 3-bromo-5-methoxypyridine (66\%) to produce a single cycloadduct diastereomer.

An iron-catalyzed multicomponent reaction of $\alpha$-diazo esters with $N$-benzylisatin derivatives and ammonia gave facile access to polyfunctional primary amines bearing 3substituted 3-hydroxyoxindole moieties in high yields and moderate diastereoselectivities (Scheme 26). ${ }^{66}$ Using 3 mol\% of $\mathrm{Fe}(\mathrm{TPP}) \mathrm{Cl}$ mediated this three-component assem- 


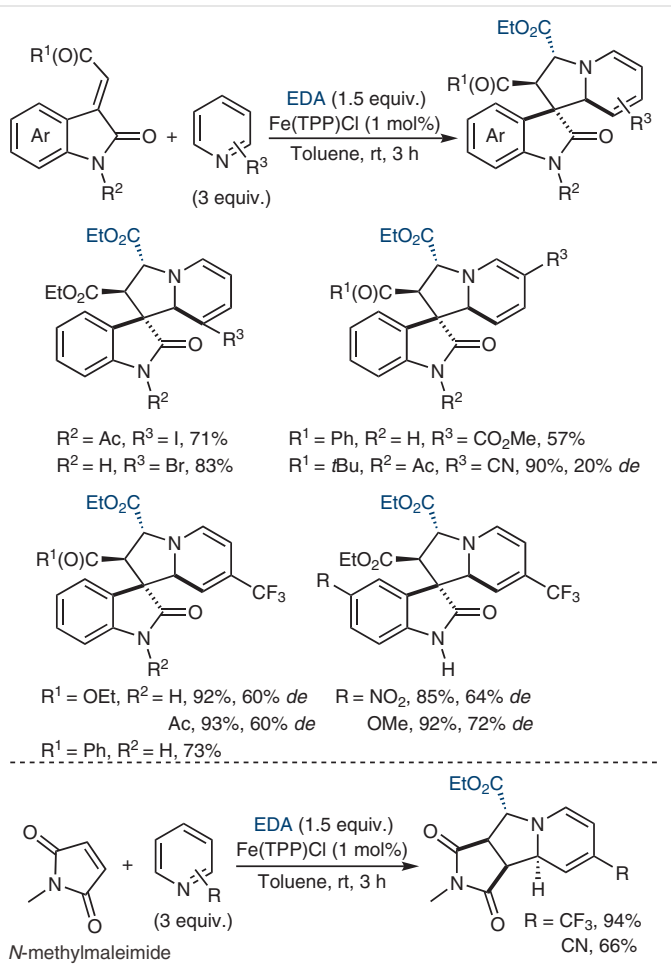

Scheme 25 Iron-catalyzed three-component stereoselective synthesis of tetrahydroindolizines

bly within $1 \mathrm{~min}$ at $65^{\circ} \mathrm{C}$ in THF. The use of various alkyl diazo compounds afforded similar diastereoselectivities of the desired three-component products in good yields.

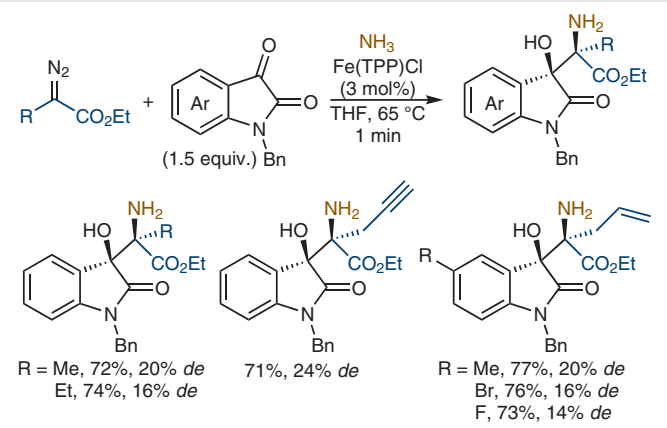

Scheme 26 Multicomponent reaction of diazo esters with $\mathrm{N}$-benzylisatin derivatives

The reaction of EDA with 1-substituted benzimidazoles in the presence of a catalytic amount of $\mathrm{Fe}(\mathrm{TPP}) \mathrm{Cl}$ ( $2 \mathrm{~mol} \%)$ generated benzimidazolium $N$-ylides which underwent 1,3dipolar cycloadditions with electron-poor disubstituted alkenes or alkynes (Scheme 27). ${ }^{67}$ This one-pot, three-component reaction allowed the facile construction of diversely substituted pyrroles in high yields (up to 95\%). The reaction scope was general and accepted different diazoacetates or diazo ketones, $\mathrm{N}$-benzylbenzimidazoles, and alkynes or alkenes in high yields, in some case the yield was almost quantitative. Control experiments and mechanistic studies resulted in the proposal of a catalytically generated benzimidazolium $N$-ylide that undergoes a [3+2] cycloaddition with the alkyne or alkene to produce the multisubstituted pyrrole. Also, cycloadditions with alkenes required the use of DDQ to favor the oxidative ring-aromatization of the pyrrolidine species to give the targeted pyrroles.

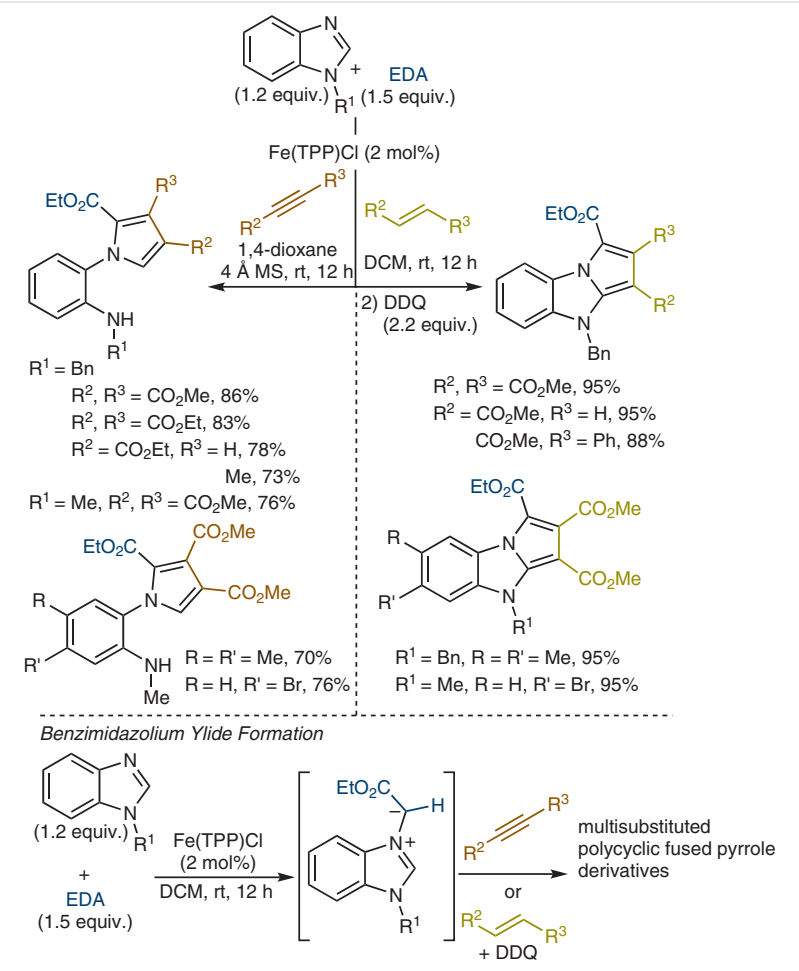

Scheme 27 1,3-Dipolar cycloaddition of benzimidazolium $N$-ylides

$\mathrm{Fe}(\mathrm{TPP}) \mathrm{Cl}$ has been used in a three-component asymmetric gem-difunctionalization of 2,2,2-trifluorodiazoethane. In the presence of arylamines, the trifluoromethylcontaining ammonium ylide is captured by an imine (made in situ from the arylamine and aldehyde) activated by a chiral BINOL-phosphoric acid co-catalyst (Scheme 28).68 The trifluoromethyl-containing chiral syn-diamines were obtained in high yields (up to 90\%) and enantioselectivities that exceed $90 \%$ ee when using $\mathrm{Fe}$ (TPP) $\mathrm{Cl}$ in $3 \mathrm{~mol} \%$ and the chiral BINOL-phosphoric acid co-catalyst in $10 \mathrm{~mol} \%$ loading at $-10{ }^{\circ} \mathrm{C}$ in toluene. The iron catalyst was highly selective and no $\mathrm{N}-\mathrm{H}$ insertion was observed with the starting amines even though the catalyst has been reported as an efficient catalyst for such a transformation (see Section 2.3). The mechanism was elucidated by DFT calculations and indicates that the formation of a free ylide, after cleavage from the iron center, is critical to react with the activated 
chiral BINOL-phosphoric acid . The BINOL-phosphoric acid acts as a chiral proton shuttle which induces the observed chirality.

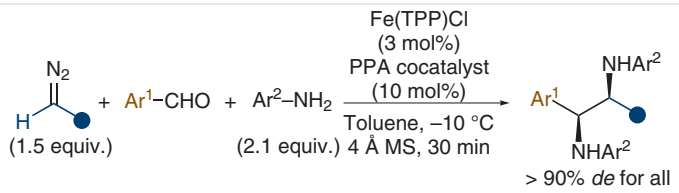

$$
\mathrm{Ar}^{1}=\underbrace{\mathrm{NHPMP}}_{\mathrm{NHPMP}}
$$

$2-\mathrm{CO}_{2} \mathrm{MeC}_{6} \mathrm{H}_{4}, 78 \%, 87 \%$ ee $2-\mathrm{BnOC}_{6} \mathrm{H}_{4}, 80 \%, 90 \%$ ee $2-\mathrm{EtOC}_{6} \mathrm{H}_{4}, 85 \%, 92 \%$ ee $2-\mathrm{BrC}_{6} \mathrm{H}_{4}, 75 \%, 80 \%$ ee 2- $\mathrm{ClC}_{6} \mathrm{H}_{4}, 77 \%, 80 \%$ ee 2-BnO-3- $\mathrm{MeOC}_{6} \mathrm{H}_{3}, 85 \%$, 88\% ee<smiles>NC(c1cccc2ccccc12)C(N)C(F)(F)F</smiles>

$\mathrm{Ar}^{2}=$

$\mathrm{Ph}, 81 \%, 93 \%$ ee $4-\mathrm{MeC}_{6} \mathrm{H}_{4}, 82 \%, 90 \%$ ee $4-\mathrm{MeOC}_{6} \mathrm{H}_{4}, 85 \%, 82 \%$ ee $4-\mathrm{BnOC}_{6} \mathrm{H}_{4}, 80 \%, 82 \%$ ee $4-\mathrm{FC}_{6} \mathrm{H}_{4}, 78 \%, 96 \%$ ee $4-\mathrm{ClC}_{6} \mathrm{H}_{4}, 82 \%, 92 \%$ ee $4-\mathrm{BrC}_{6} \mathrm{H}_{4}, 80 \%, 92 \%$ ee

Scheme 28 Three component asymmetric gem-difunctionalization of 2,2,2-trifluorodiazoethane

\section{Miscellaneous}

In certain cases, an iron catalyst can leave the dinitrogen of a diazo compound intact, and this allows interesting reactivity. Among these instances is the synthesis of hydrazones through an iron-catalyzed hydroamination as an alternative to olefin hydroaminations that use $\mathrm{NaN}_{3}$ (Scheme 29). ${ }^{69}$ This reaction used $\mathrm{Fe}(\mathrm{acac})_{3}(10 \mathrm{~mol} \%)$ and $\mathrm{PhSiH}_{3}$ for the hydroamination of various alkenes with a wide scope of acceptor/acceptor and donor/acceptor diazo compounds in moderate and high yields. An intramolecular hydroamination of a variety of olefin-containing diazo compounds allowed access to 6-, 7-, and 8-membered cyclic hydrazones in good yields (up to $85 \%$ ).

A mild and efficient halogenation of $\alpha$-halomethyl ketones starting from $\alpha$-diazo ketones used $\mathrm{FeX}_{3}$ salts and silica gel (Scheme 30). ${ }^{70}$ This interesting approach used 0.5 equiv. of the iron salt $\left(\mathrm{FeCl}_{3}\right.$ or $\left.\mathrm{FeBr}_{3}\right)$ in DCM at room temperature and gave the respective $\alpha$-chloro or $\alpha$-bromomethyl ketones in high yields. It was suggested that the formation of the iron carbene intermediate produced the halogen anion which attacks the carbene center and is then protonated by silica.

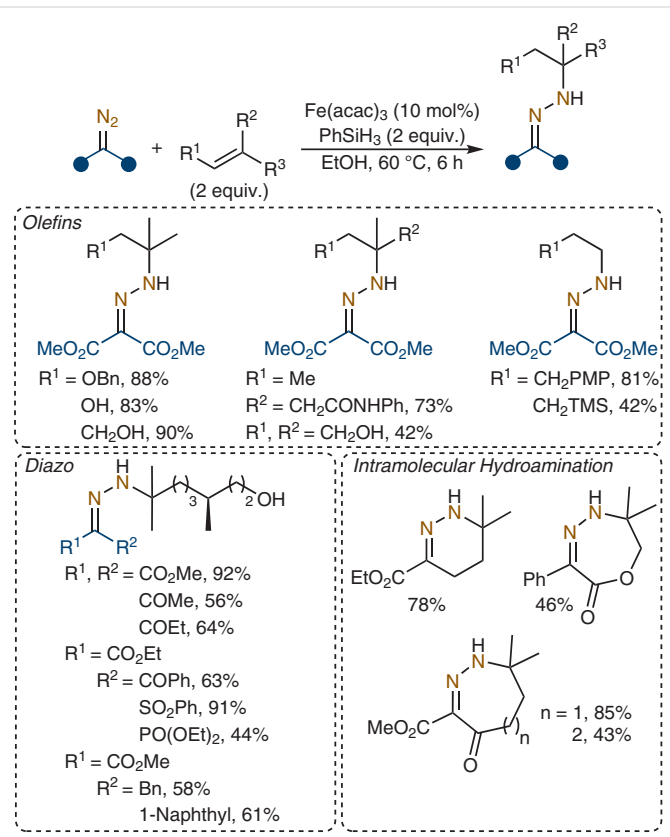

Scheme 29 Hydroamination of olefins with diazo compounds

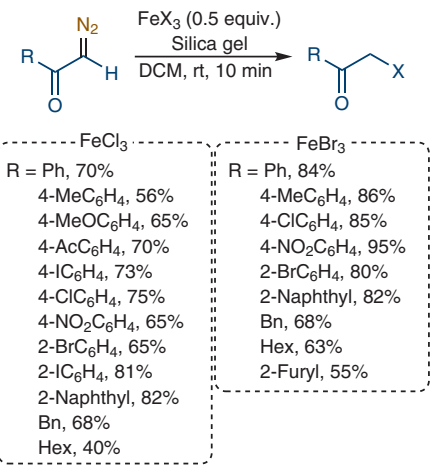

Scheme 30 Synthesis of $\alpha$-halomethyl ketones from $\alpha$-diazo ketones

\section{Conclusion}

Not only are diazo compounds extremely versatile, but also their reactivity with iron catalysts demonstrates their wide application range. There is no doubt that there has been mounting interest in iron-mediated chemistry with diazo compounds. This attention is due to its selectivity, efficiency, and availability. Numerous breakthroughs have been made in the field of iron catalysis with diazo compounds, and they have opened up doors to hitherto inaccessible transformations. Iron-catalyzed asymmetric transformations with diazo compounds remain one of the biggest challenges. Catalysts based on abundant iron constitute attractive alternatives to well-developed noble metal cata- 
lysts. The development of an even wider variety of iron catalysts is certainly desirable in order to further complete the organic chemist toolbox in sustainable catalytic processes.

After submission of this article, a similar review covering Fe-catalyzed transformations with diazo compounds was published. ${ }^{71}$

\section{Note added in proof}

After submission of this article, a similar review covering Fe-catalyzed transformations with diazo compounds was published. ${ }^{71}$

\section{Funding Information}

This work was supported by the Natural Sciences and Engineering Research Council of Canada (NSERC) Discovery Grant RGPIN-201704272, the Fonds Québécois de la Recherche sur la Nature et les Technologies (FQRNT) (Centre in Green Chemistry and Catalysis) Strategic Cluster FRQNT-2020-RS4-265155-CCVC, and Université Laval.

\section{Acknowledgment}

N.T. thanks the Natural Sciences and Engineering Research Council of Canada (NSERC) for a PSG D award.

\section{References}

(1) Anastas, P. T.; Zimmerman, J. B. Green Chem. 2019, 21, 6545.

(2) Constable, D. J. C.; Dunn, P. J.; Hayler, J. D.; Humphrey, G. R.; Leazer, J. L.; Linderman, R. J.; Lorenz, K.; Manley, J.; Pearlman, B. A.; Wells, A.; Zaksh, A.; Zhangf, T. Y. Green Chem. 2007, 9, 411.

(3) Bauer, I.; Knölker, H.-J. Chem. Rev. 2015, 115, 3170.

(4) Ollevier, T. Catal. Sci. Technol. 2016, 6, 41.

(5) Wenger, O. S. Chem. Eur. J. 2019, 25, 6043.

(6) Enthaler, S.; Junge, K.; Beller, M. Angew. Chem. Int. Ed. 2008, 47, 3317.

(7) Ford, A.; Miel, H.; Ring, A.; Slattery, C. N.; Maguire, A. R.; McKervey, M. A. Chem. Rev. 2015, 115, 9981.

(8) Doyle, M. P.; McKervey, M. A.; Ye, T. Modern Catalytic Methods for Organic Synthesis with Diazo Compounds: From Cyclopropanes to Ylides; Wiley-Interscience: New York, 1998, 652.

(9) Davies, H. M. L.; Denton, J. R. Chem. Soc. Rev. 2009, 38, 3061.

(10) Gillingham, D.; Fei, N. Chem. Soc. Rev. 2013, 42, 4918.

(11) Damiano, C.; Sonzini, P.; Gallo, E. Chem. Soc. Rev. 2020, 49, 4867.

(12) Empel, C.; Jana, S.; Koenigs, R. M. Molecules 2020, 25, 1.

(13) Allouche, E. M. D.; Charette, A. B. Synthesis 2019, 51, 3947.

(14) Cho, Y. H.; Kim, J. H.; An, H.; Ahn, K. H.; Kang, E. J. Adv. Synth. Catal. 2020, 362, 2183.

(15) Doyle, M. P.; Forbes, D. C. Chem. Rev. 1998, 98, 911.

(16) Seitz, W. J.; Saha, A. K.; Hossain, M. M. Organometallics 1993, 12, 2604.

(17) Zhu, S.-F.; Zhou, Q.-L. Nat. Sci. Rev. 2014, 1, 580.

(18) Li, X.; Curran, D. P. J. Am. Chem. Soc. 2013, 135, 12076.

(19) Cheng, Q. Q.; Zhu, S. F.; Zhang, Y. Z.; Xie, X. L.; Zhou, Q. L. J. Am. Chem. Soc. 2013, 135, 14094.

(20) Chen, D.; Zhang, X.; Qi, W. Y.; Xu, B.; Xu, M. H. J. Am. Chem. Soc. 2015, 137, 5268.
(21) Kan, S. B. J.; Huang, X.; Gumulya, Y.; Chen, K.; Arnold, F. H. Nature 2017, 552, 132.

(22) Huang, X.; Garcia-Borràs, M.; Miao, K.; Kan, S. B. J.; Zutshi, A.; Houk, K. N.; Arnold, F. H. ACS Cent. Sci. 2019, 5, 270.

(23) Chen, K.; Huang, X.; Zhang, S.-Q.; Zhou, A. Z.; Kan, S. B. J.; Hong, X.; Arnold, F. H. Synlett 2019, 30, 378

(24) Wu, J.; Panek, J. S. J. Org. Chem. 2011, 76, 9900.

(25) Davies, H. M. L.; Huby, N. J. S.; Cantrell, W. R. Jr.; Olive, J. L. J. Am. Chem. Soc. 1993, 115, 9468.

(26) Franz, A. K.; Wilson, S. O. J. Med. Chem. 2013, 56, 388.

(27) Keipour, H.; Carreras, V.; Ollevier, T. Org. Biomol. Chem. 2017, $15,5441$.

(28) Keipour, H.; Ollevier, T. Org. Lett. 2017, 19, 5736.

(29) Tanbouza, N.; Keipour, H.; Ollevier, T. RSC Adv. 2019, 9, 31241.

(30) Xu, L. W.; Li, L.; Lai, G. Q.; Jiang, J. X. Chem. Soc. Rev. 2011, 40, 1777.

(31) Gu, H.; Han, Z.; Xie, H.; Lin, X. Org. Lett. 2018, 20, 6544.

(32) Kan, S. B. J.; Lewis, R. D.; Chen, K.; Arnold, F. H. Science 2016, $354,1048$.

(33) Lewis, R. D.; Garcia-Borràs, M.; Chalkley, M. J.; Buller, A. R.; Houk, K. N.; Kan, S. B. J.; Arnold, F. H. Proc. Natl. Acad. Sci. U. S. A. 2018, 115, 7308.

(34) Antos, J. M.; McFarland, J. M.; Iavarone, A. T.; Francis, M. B. J. Am. Chem. Soc. 2009, 131, 6301.

(35) Chan, A. O.; Ho, C. M.; Chong, H. C.; Leung, Y. C.; Huang, J. S.; Wong, M. K.; Che, C. M. J. Am. Chem. Soc. 2012, 134, 2589.

(36) Srour, H. F.; Le Maux, P.; Chevance, S.; Carrie, D.; Le Yondre, N.; Simonneaux, G. J. Mol. Catal. A: Chem. 2015, 407, 194.

(37) Yoo, J.; Park, N.; Park, J. H.; Park, J. H.; Kang, S.; Lee, S. M.; Kim, H. J.; Jo, H.; Park, J.-G.; Son, S. U. ACS Catal. 2015, 5, 350.

(38) Zhou, M.; Zhang, H.; Xiong, L.; He, Z.; Wang, T.; Xu, Y.; Huang, K. Polym. Chem. 2017, 8, 3721.

(39) Pandit, R. P.; Kim, S. H.; Lee, Y. R. Adv. Synth. Catal. 2016, 358, 3586.

(40) Empel, C.; Hock, K. J.; Koenigs, R. M. Org. Biomol. Chem. 2018, 16, 7129.

(41) Wang, Z. J.; Peck, N. E.; Renata, H.; Arnold, F. H. Chem. Sci. 2014, $5,598$.

(42) Moore, E. J.; Steck, V.; Bajaj, P.; Fasan, R. J. Org. Chem. 2018, 83, 7480.

(43) Cailler, L. P.; Martynov, A. G.; Gorbunova, Y. G.; Tsivadze, A. Y.; Sorokin, A. B. J. Porphyrins Phthalocyanines 2019, 23, 497.

(44) Shen, H.-Q.; Wu, B.; Xie, H.-P.; Zhou, Y.-G. Org. Lett. 2019, 21, 2712.

(45) Yates, P. J. Am. Chem. Soc. 1952, 74, 5376.

(46) Keipour, H.; Jalba, A.; Tanbouza, N.; Carreras, V.; Ollevier, T. Org. Biomol. Chem. 2019, 17, 3098.

(47) Röske, A.; Alt, I.; Plietker, B. ChemCatChem 2019, 11, 5260.

(48) Ren, Y. Y.; Zhu, S. F.; Zhou, Q. L. Org. Biomol. Chem. 2018, 16, 3087.

(49) Tyagi, V.; Bonn, R. B.; Fasan, R. Chem. Sci. 2015, 6, 2488.

(50) Chen, K.; Zhang, S.-Q.; Brandenberg, O. F.; Hong, X.; Arnold, F. H. J. Am. Chem. Soc. 2018, 140, 16402.

(51) Doyle, M. P.; Griffin, J. H.; Chinn, M. S.; van Leusen, D. J. Org. Chem. 1984, 49, 1917.

(52) Tyagi, V.; Sreenilayam, G.; Bajaj, P.; Tinoco, A.; Fasan, R. Angew. Chem. Int. Ed. 2016, 55, 13562.

(53) Hock, K. J.; Mertens, L.; Hommelsheim, R.; Spitzner, R.; Koenigs, R. M. Chem. Commun. 2017, 53, 6577.

(54) Zhang, X.; Liu, Z.; Yang, X.; Dong, Y.; Bi, X.; Virelli, M.; Zanoni, G.; Anderson, E. A.; Bi, X. Nat. Commun. 2019, 10, 284. 
(55) Ning, Y.; Zhang, X.; Gai, Y.; Dong, Y.; Sivaguru, P.; Wang, Y.; Reddy, B. R. P.; Zanoni, G.; Bi, X. Angew. Chem. Int. Ed. 2020, 59, 6473.

(56) Xu, X.; Li, C.; Tao, Z.; Pan, Y. Green Chem. 2017, 19, 1245.

(57) Xu, X.; Li, C.; Xiong, M.; Tao, Z.; Pan, Y. Chem. Commun. 2017, 53, 6219.

(58) Empel, C.; Hock, K. J.; Koenigs, R. M. Chem. Commun. 2019, 55, 338.

(59) Yan, X.; Li, C.; Xu, X.; Zhao, X.; Pan, Y. Adv. Synth. Catal. 2020, 362,2005

(60) Zou, H.-B.; Yang, H.; Liu, Z.-Y.; Mahmood, M. H. R.; Mei, G.-Q.; Liu, H.-Y.; Chang, C.-K. Organometallics 2015, 34, 2791.

(61) Karaca, O.; Anneser, M. R.; Kueck, J. W.; Lindhorst, A. C.; Cokoja, M.; Kühn, F. E. J. Catal. 2016, 344, 213.

(62) Liu, P.; Zhu, C.; Xu, G.; Sun, J. Org. Biomol. Chem. 2017, 15, 7743.
(63) Abeykoon, B.; Devic, T.; Grenèche, J.-M.; Fateeva, A.; Sorokin, A. B. Chem. Commun. 2018, 54, 10308.

(64) Day, J.; McKeever-Abbas, B.; Dowden, J. Angew. Chem. Int. Ed. 2016, 55, 5809.

(65) Douglas, T.; Pordea, A.; Dowden, J. Org. Lett. 2017, 19, 6396.

(66) Ma, C.; Chen, J.; Xing, D.; Sheng, Y.; Hu, W. Chem. Commun. 2017, 53, 2854

(67) Zhou, K.; Bao, M.; Huang, J.; Kang, Z.; Xu, X.; Hu, W.; Qian, Y. Org. Biomol. Chem. 2020, 18, 409.

(68) Li, J.; Zhang, D.; Chen, J.; Ma, C.; Hu, W. ACS Catal. 2020, 10, 4559.

(69) Zheng, J.; Qi, J.; Cui, S. Org. Lett. 2016, 18, 128.

(70) Shi, X.; Zhang, L.; Yang, P.; Sun, H.; Zhang, Y.; Xie, C.; Zhen, O.-y.; Wang, M. Tetrahedron Lett. 2018, 59, 1200.

(71) Batista, V. F.; Pinto, D. C. G. A.; Silva, A. M. S. ACS Cat. 2020, 10, 10096. 